\title{
Approaches for the Development of New Anti-Trypanosoma cruzi Agents
}

\author{
Diogo Rodrigo Magalhães Moreira ${ }^{1, *}$, Ana Cristina Lima Leite ${ }^{1}$, Ricardo Ribeiro dos Santos ${ }^{2,3}$ and \\ Milena B. P. Soares ${ }^{2,3}$
}

\begin{abstract}
${ }^{1}$ Laboratório de Planejamento, Avaliação e Síntese de Fármacos - LABSINFA, Departamento de Ciências Farmacêuticas, Universidade Federal de Pernambuco (UFPE), Rua Prof. Artur Sá S/N, Cidade Universitária, 50740-520, Recife, PE, Brazil; ${ }^{2}$ Centro de Pesquisas Gonçalo Moniz, Fundação Oswaldo Cruz. Rua Waldemar Falcão, 121. Candeal 40296-710 - Salvador, BA - Brazil and ${ }^{3}$ Hospital São Rafael. Av. São Rafael, 2152. São Marcos 41253-190 - Salvador, BA, Brazil
\end{abstract}

\begin{abstract}
The recent highlights on the biochemical pathways of Trypanosoma cruzi have allowed a significant improvement in the development of new strategies for drug design and also in the understanding of the mechanisms of action of new trypanocidal agents. Several biochemical pathways of fundamental importance and validated targets (e.g. cysteine protease cruzain, trypanothione reductase, trans-sialidase) of $T$. cruzi have proved usefulness for drug development in many examples of new candidates to anti-T. cruzi drugs. This review will focus on some approaches used for the design of new potential trypanocidal agents, exploring modern concepts of medicinal chemistry such as bioisosterism, molecular hybridization, bioinspired design in lead compounds, as well as the complexation of transition metals with bioactive ligands. The examples discussed in this article may serve as lessons for the antitrypanosomal drug design.
\end{abstract}

Key Words: Chagas' disease, chemotherapy, rational drug design, medicinal chemistry, Trypanosoma cruzi.

\section{INTRODUCTION}

American trypanosomiasis or Chagas' disease continues to place a heavy burden on millions of people in Latin American countries. Due to the lack of a vaccine, patient therapy is heavily reliant on chemotherapy with benznidazole (Rochagan $\left.{ }^{\circledR}\right)$, the only World Health Organizationrecommended drug, but concerns over drug resistance, the high toxicity, and the low efficacy of this drug, especially during the chronic phase of infection, encourage the search for new drugs [1].

The 70' and 80' decades of anti-T. cruzi drug development have resulted in structurally similar classes of compounds, mainly based on nitro-heterocyclics such as benznidazole (Fig. (1)). Benznidazole and other nitro-heterocyclic compounds act through the formation of free radicals and/or electrophilic metabolites, with consequent oxidative stress and by trypanothione depletion in parasites. This has attracted attention to a strategy aiming to attach a nitro group in chemical libraries during the planning of potential antitrypanosomal agents [2]. However, this strategy is not preferred for drug development because of the remarkable lack of selectivity for action in parasites, therefore resulting in compounds with high mutagenic-inducing potential to mammalian cells and with toxicity inherent to nitro group-containing heterocyclic. Undoubtedly few advances in drug development

\footnotetext{
*Address correspondence to this author at the Laboratório de Planejamento, Avaliação e Síntese de Fármacos - LABSINFA, Departamento de Ciências Farmacêuticas, Universidade Federal de Pernambuco (UFPE), Rua Prof. Artur Sá S/N, Cidade Universitária, 50740-520, Recife, PE, Brazil; Tel: +0558133418511; Fax: +0558121268510;

E-mail:diogollucio@yahoo.com.br
}

on antitrypanosomal chemotherapy were achieved, and no drug emerged as an effective candidate to clinical trials on Chagas' disease in the last 30 years [3].

During the last decade, other classes of synthetic compounds were also planned aiming to act by causing oxidative stress on the parasite in a manner very similar to nitroheterocyclics, such as naphthoquinones derivatives. In this case, after the screening of several libraries of congeneric series based on 1,4-naphthoquinones, including the optimization of lead compounds, no suitable candidates for preclinical assay were obtained [4].

Because of the low advance in antitrypanosomal chemotherapy in the 90thies, medicinal chemistries have made considerable efforts over the last decade to push up the drugability of "hits" via more elaborated and rational designs of candidates to anti- $T$. cruzi drugs [5]. Indeed, significant progresses have been made in the design of drug candidates active in kinetoplastid protozoan, highlighting the rules for important targets and biochemical pathways.

Recent reports have pointed out the gaps, needs and trends to increase the opportunity of success during the research for new lead compounds, candidate to drugs against neglected disease, such as Chagas' disease. It should be noted that lead discovery tends to occur if a good strategy of drug design is employed. Among the known targets for $T$. cruzi, the most promising approaches to guide the drug design are the planning of new chemical entities based on molecular targets and the use of lead compounds from validated "hit compounds" [6,7].

Thus, this review will focus on the some approaches used for the design of new potential trypanocidal agents, explor- 


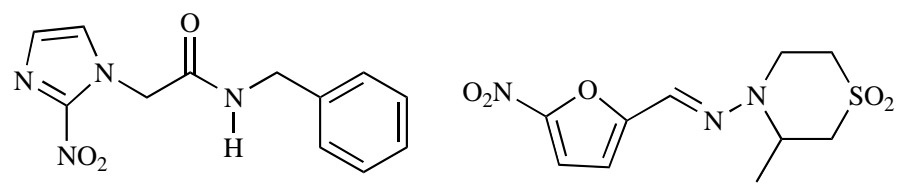

Benznidazole<smiles>Cn1c([N+](=O)[O-])cnc1-c1nnc(N)s1</smiles>

Nifurtimox

Megazol<smiles>[R16]c1ccc(NC(=O)CN(C)C)cc1</smiles>

Fig. (1) Representative examples of nitro-heterocyclic endowed with anti-T. cruzi activity.

ing useful concepts on the medicinal chemistry: bioisosterism, molecular hybridization, bioinspired design in lead compounds, as well as the complexation of transition metals with bioactive ligands (bioinorganics). This discussion may be useful for the design of antitrypanosomal drugs preventing many setbacks and increasing the potential of development of new lead compounds.

\section{ANTITRYPANOSOMAL AGENTS TARGETING DNA: BIOINSPIRED DESIGN IN LEAD-COMPOUNDS}

The strategy of antitrypanosomal drug design targeting on DNA topoisomerases has attracted attention since theses enzymes possess an essential role in the replication of $T$. cruzi DNA, and also because there is a large number of potent inhibitors that can be readily marketed as chemotherapeutic agents. This approach has proven to be well-valuable for antibacterial and antivirus therapy [8].
For this reason, several commercially available libraries of DNA topoisomerases (type I and II) inhibitors, such as anthracyclines, camptothecins, mitoxantrones, acridines and fluoroquinolones have been screened for in vitro activity against the bloodstream form (trypomastigotes) of $T$. cruzi (Fig. (2)). So far most of the DNA topoisomerases inhibitors tested demonstrated low efficacy to inhibit the T. cruzi, and only a few active DNA topoisomerases inhibitors were found [9]. Among them, DNA topoisomerase I inhibitors based on Camptothecins and analogues were found to be potent antiTrypanosoma cruzi agents in micromolar range [10,11].

Taking the Coralline structure it was possible to establish some SAR, as illustrated by the bioisosteric relationship existing between the orto-methoxy groups and the methylenedioxy ring, as well as the importance of position of fused rings onto this scaffold (Fig. (3)) [9, 12]. Although Camptothecin, Coralline and other structurally-related analogues<smiles>CC[C@@]1(O)C(=O)OCc2c1cc1n(c2=O)Cc2cc3ccccc3nc2-1</smiles><smiles>COc1cc2cc3c4cc(OC)c(OC)cc4cc[n+]3c(C)c2cc1OC</smiles>

Coraline<smiles>CC[C@@]1(O)C(=O)OCc2c1cc1n(c2=O)Cc2cc3c(CN(C)C)c(O)ccc3nc2-1</smiles>

Topotecan<smiles>Cc1c2cnccc2c(C)c2c1[nH]c1ccccc12</smiles>

Ellipticine<smiles>Cc1cc(O)c2c(c1)C(=O)C(c1c(C)cc3c(c1O)C(=O)C=CC3=O)=CC2=O</smiles><smiles>[R]N1CCN(c2cc3c(cc2F)c(=O)c(C(=O)O)cn3C2CC2)CC1</smiles>

Ciprofloxacin $(\mathrm{R}=\mathrm{H})$ and analogues

Fig. (2) Structures of DNA topoisomerase and DNA gyrase inhibitors tested against T. cruzi and T. brucei. 


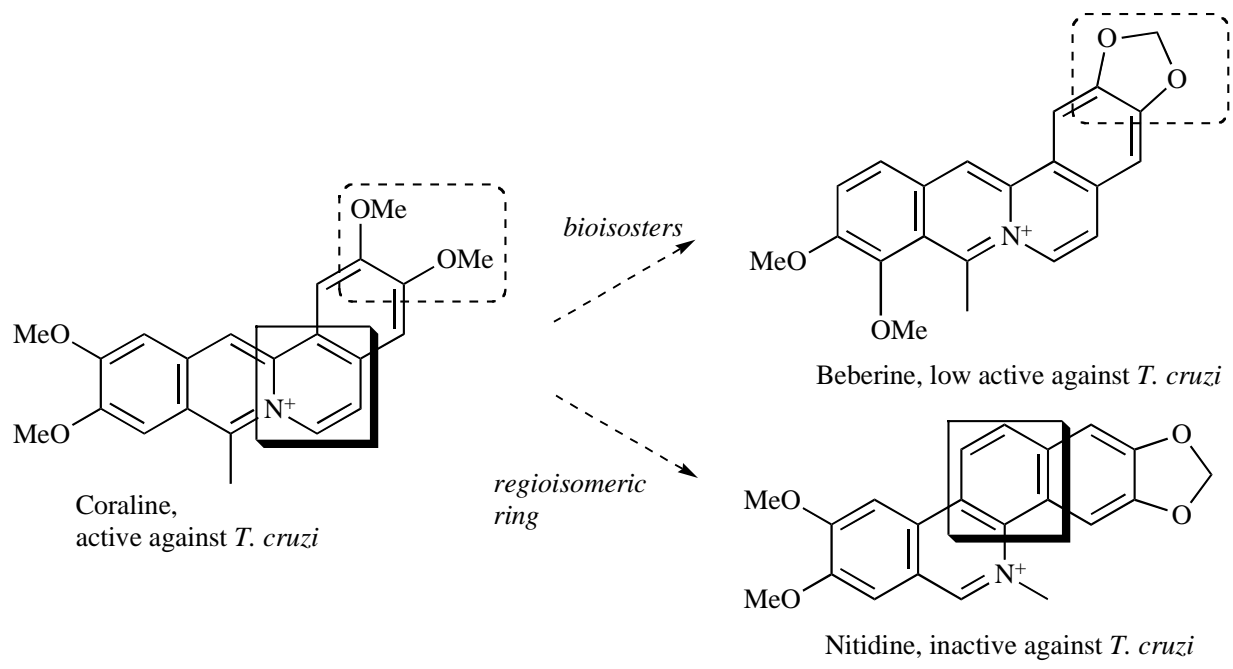

Fig. (3) SAR for DNA topoisomerases inhibitors as anti-T. cruzi

possess good in vitro antitrypanosomal activity and had low cytotoxicity, no new reports dealing with SAR or in vivo studies with these compounds appeared in the literature to our knowledge.

It is worth relating that particular emphasis has been done to test these compounds against $T$. brucei, also yielding attractive results but, similar to $T$. cruzi, very few studies have been conducted underline the efficacy of DNA topoisomerases inhibitors in vivo in this kinetoplastid infection [13].

From this survey, two questions can be raised about the strategy of developing DNA topoisomerases inhibitors as anti-T. cruzi agents. The first is why is there a lack of efforts to optimize lead compounds based on this target. The second is do known inhibitors of the DNA topoisomerase affect the pathology appropriately? It is evident that targeting parasite DNA topoisomerases for drug discovery requires the synthesis of more specific chemical libraries.

Concerning the rule of DNA-intercalating drugs, the acridine has been found as an attractive subunit for the use on the drug design of antitrypanosomal agents. Is well recognized that acridine binds to DNA by perpendicular intercalation, although other target and pathways are also involved [14]. In this strategy, the concepts of molecular hybridization of a acridine subunit coupled with another pharmacophore unit provides good starting point to explore DNA-intercalating drugs acting also against $T$. cruzi, as illustrated in Fig. (4).

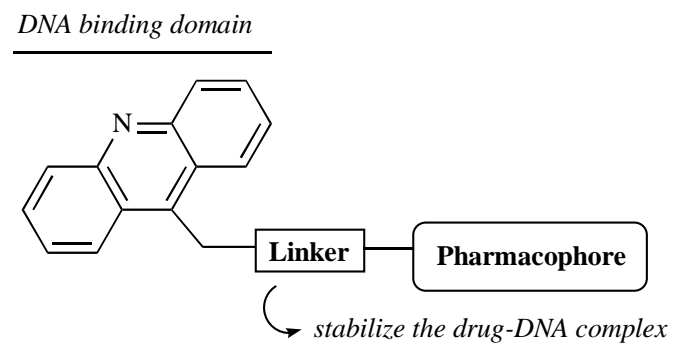

Fig. (4) Strategy using DNA intercalation with acridine subunit.
The group of Sergheraert developed a large library of bisacridines, exploring the impact of the volume and size of the linker on the acridine structure. Applying this design, was hypothesized that the variation of linker by attaching bulky groups will could contribute to improve the intercalation with DNA and thus the antitrypanosomal activities (Fig. (5)). The pharmacological results obtained with these series showed only poor activities against $T$. cruzi amastigotes, while very good results against $T$. brucei were found. In addition, was suggested that bis-acridines exert their inhibitory effects by binding to DNA rather than to the TRTc enzyme [15].

In a similar context, Caffrey and co-workers [16] explored another library of 18 bis-acridines containing several space groups as linkers and the full screening was done against a panel of nine parasites, including $T$. b. brucei and T. cruzi (Fig. (6)). During the planning of this series, the chemical nature and dimension of linker were investigated. In this study none of the bis-acridines were active against $T$. cruzi amastigotes when the activity against $T$. brucei was remarkable $\left(\mathrm{EC}_{50}\right.$ range 10 to $\left.100 \mathrm{nM}\right)$ and comparable to the reference drug (Melarsoprol).

It is interesting to point out that, different from bisacridines, the acridine monomers endowed with antitrypanosomal activity against cell cultures of parasites were found to exert their biological action though the inactivation of TRTc instead of acting on the DNA structures, as expected. These illustrative examples show that acridine is a suitable subunit for planning anti-T. cruzi agents when targeting the TRTc enzyme, but not for targeting the DNA structure.

\section{TRANS-SIALIDASE INHIBITORS}

Among the most recent strategies for designing new specific TcTS inhibitors there is a significant predominance on the use of bioisosterism as an approach to molecular modification in the sialic acid structure. Undoubtedly, part of the strategies applied in rational design of trans-sialidase inhibitors already have been successfully used during the drug design of influenza neuraminidase enzyme inhibitors, due to the strong similarly of both targets and catalytic mechanism [17]. 

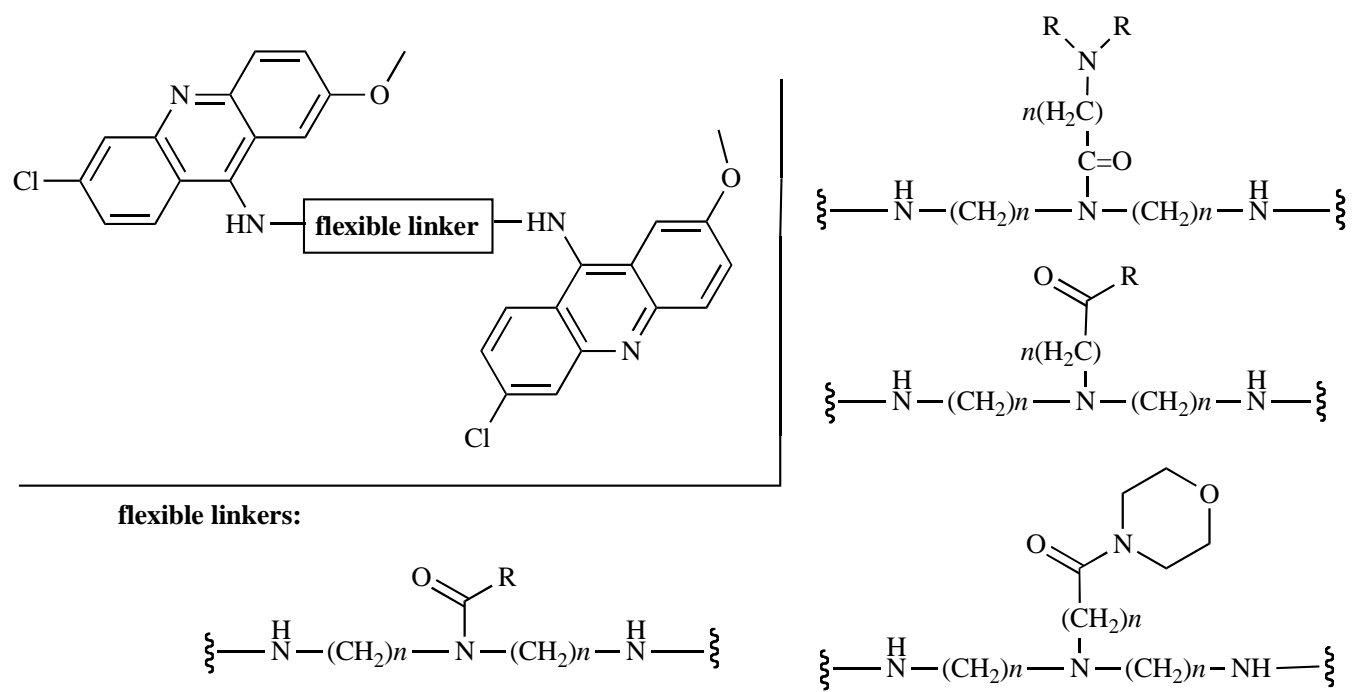

Fig. (5) Structures of bis-acridines planned as anti-T. cruzi agents via DNA intercalation.

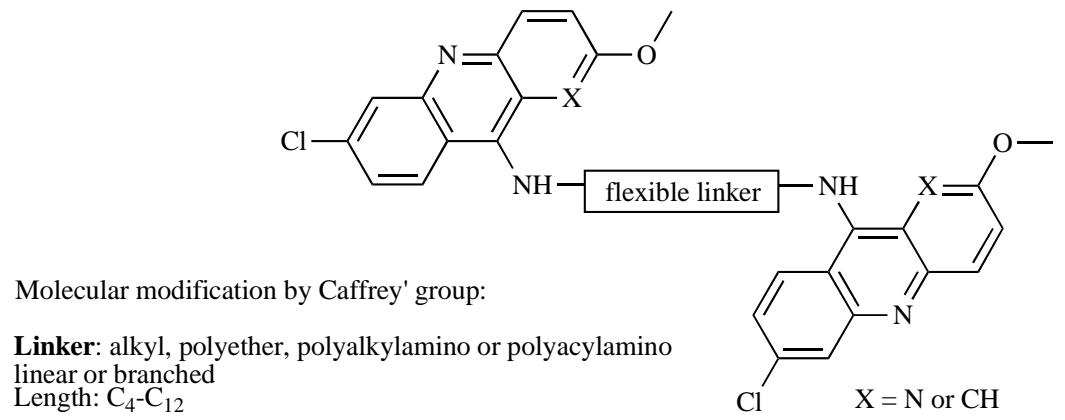

Fig. (6) Library of bis-acridines acting as DNA binders, tested against multiple parasites.

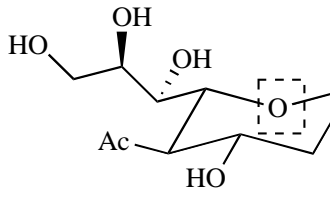

sialic acid
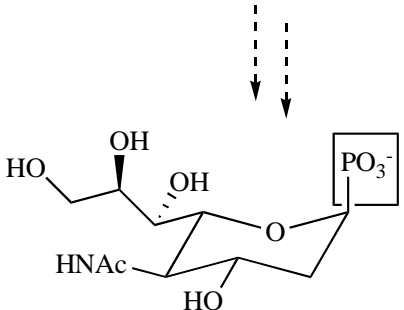

sialic acid mimetic (II) $(\alpha$-anomer $)$

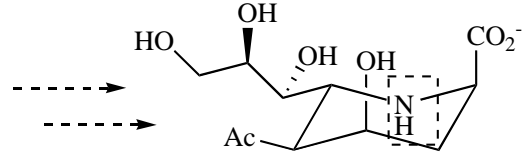

$N$-sialic acid mimetic (I)

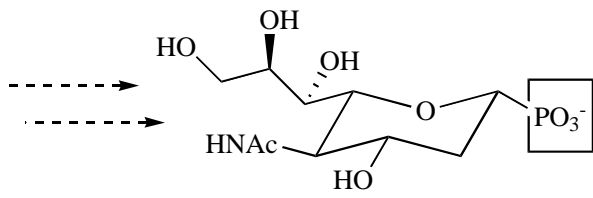

sialic acid mimetic (III) $(\beta$-anomer)

Fig. (7) Strategies of molecular modification on the structure of sialic acid.

To find more specific $T$. cruzi trans-sialidase inhibitors, Engstler and co-workers developed the bioisosteric change between oxygen atom (present in the structure of sialic acid) and nitrogen atom, as well as the exchange of carboxylic acid by phosphate group (Fig. (7)) [18]. The results obtained with pure enzyme preparations revealed that the sialic acid mimetic I and phosphate acid mimetic II and III were inactive to inhibit the TcTS. These results could be due to the acid-base properties of structure $\mathbf{I}$ with modification of $\mathrm{pKa}$ when compared with sialic acid and, in the case of II and III, probably by the remarkable difference of size, electronic distribution and capacity to make $\mathrm{H}$-bonds into the enzyme 
of phosphate group when compared to carboxylic acid. It is interesting to relate that both II and III were found as good Influenza neuraminidase inhibitors and X-ray crystallography data show distinct binds to the enzyme. Although possessing very similar hydrogen bonding, electrostatic and van der Waals interactions, ligand II binds to neuraminidase on a "chair" conformation, while III bind on a "boat" conformation [19].

Later on, considering the transition-state structures of sialic acid reactions and the bioisosteric replacement of the ring involving the conformational restriction but maintaining the basic pharmacophore (Fig. (8)), DANA and Zanamivir were tested, but both compounds failed as TcTS inhibitors, indicating that the modification in the heterocyclic ring is not a good strategy to find TcTS specific inhibitors [20]. It is also interesting to note that Zanamivir and DANA are potent Influenza neuraminidase inhibitors.

Other example of SAR applied on the TcTS inhibitors was the exchange of pyran by cyclohexene with simultaneous change of carboxylic acid by phosphonate (Fig. (9)), as exemplified by Oseltamivir and analogues. Regarding this strategy of drug design, it would be expected significant differences on the binding pattern onto TcTS structure of these sialic acid mimetics. However, this strategy only allowed to produce moderate to weak inhibitors $\left(\mathrm{IC}_{50} \sim 5-10 \mu \mathrm{M}\right)$, demonstrating that the replacement of heterocyclic ring during sialic acid structure is deleterious for biological activity [21].

In the quest for new structure underling TcTS target, Ferrero-Garcia and co-workers [22] and later on Neres and coworkers [23] investigated novel non-sugar scaffolds as TcTS inhibitors. During these efforts, a large number of aryl- and pyridoxyl-phosphates and aryl- and pyridoxyl-carboxylic acids were planned and tested against the pure enzyme, and docking studies were conducted to help on the understanding of SARs (Fig. (10)). Three of the compounds synthesized were found to be moderate TcTS inhibitors, especially compounds 4-acetylamino-3-hydroxymethylbenzoic acid and 5acetylamino-6-aminopyridine-2-carboxylic acid.

Also, during this work, other chemical templates were investigated, allowing the gathering of SARs informations. These works are of great interest because they have provided a new series of non-sugar compounds as template for TcTS

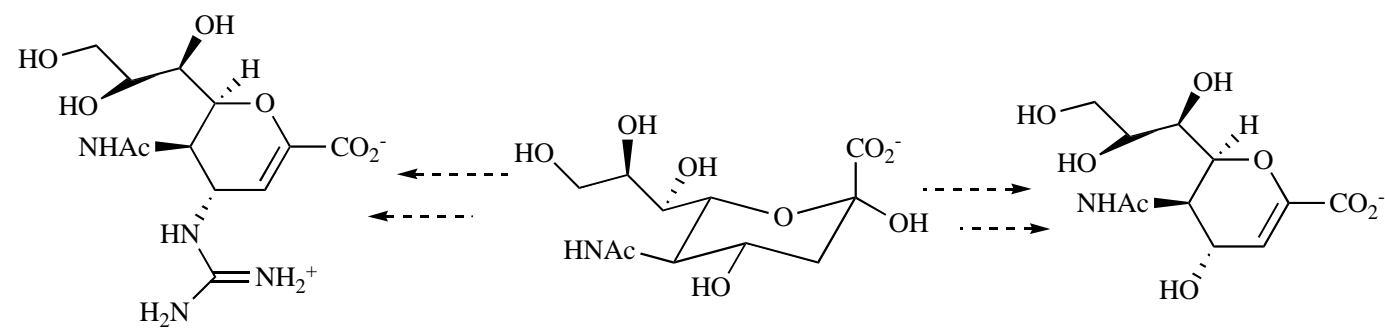

Zanamivir, inactive

Sialic acid

DANA, weak TcTS inhibitor

Fig. (8) Key structural modification on the structure of sialic acid.

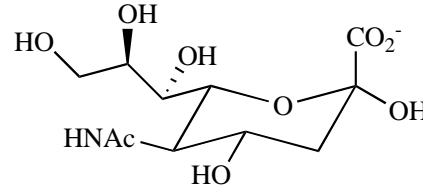

sialic acid

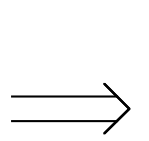

NHA<smiles>N=[Pb]C1=CC[C@@H](CN)[C@H](O)C1</smiles>

$\mathrm{HO}$
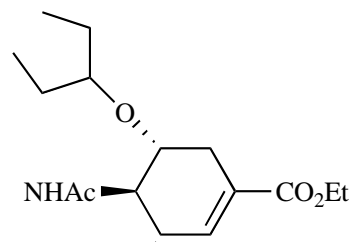

${ }^{+} \mathrm{NH}_{3} \mathrm{O}_{4} \mathrm{P}^{-}$

oseltamivir

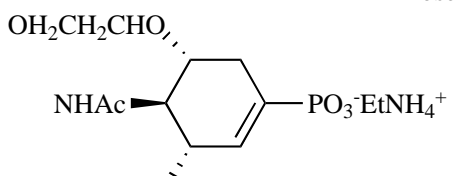

$\mathrm{HO}$

Fig. (9) Sialic acid and its more conformationally restrained analogues.
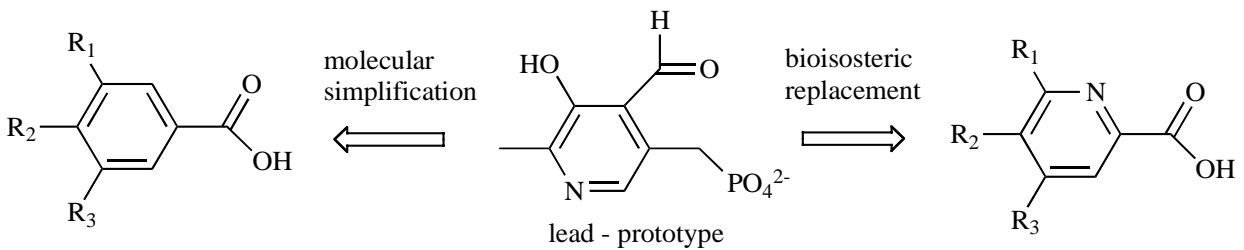

Fig. (10) Design of new non-sugar scaffolds as TcTS inhibitors. 
target, representing a very important advance on the pipeline of medicinal chemistry targeting TcTS enzyme. Thus, this pharmacophore point may be useful in further database searching to find novel T. cruzi trans-sialidase inhibitors.

More recently, the group of Prof. Withers has achieved success during the drug design of more specific and potent TcTS inhibitors [24]. Using the mechanism-based inhibitors and transition-state analogue inhibitors strategies, the hypothesis of attach a more electronegative substituent at or near the anomeric carbon was found to be a good way to generate new TcTS inhibitors with likely catalytic-inhibitory mechanism differences (Fig. (11)). The hydroxyl fluorosialic acid showed moderate ability to inhibit the enzyme but, after removal of substrate, the recovery of enzymatic activity by transglycosylation reaction was observed. By contrast, the 3fluorosialyl fluoride showed higher capacity to inactive the enzyme than hydroxyl fluorosialic, adopting a time-dependent fashion response and binding covalently onto the enzyme. Here again the recovery of enzymatic activity was observed when the inhibitor was used at low concentration or after removal.

Later on, a second generation of 3-fluorosialic acid was development, considering the structure of 3-fluorosialyl fluoride as a hit compound and exploring structural modifications at C-9 position on the prototype [25]. The study of kinetics and crystal structure determination by X-ray crystallographic analysis revealed that the change of hydroxyl by free amino group is not good to activity, whereas the replacement of amino group by azido $\left(\mathrm{N}_{3}\right)$ or amide groups increase the biological activity, improving the inactivation profile on the enzyme when compared to the prototype. The X-ray crystallographic analyses highlight details on the binding pattern for 9-arylamide-3-fluorosialic acid, suggesting that bulky substituents occupy and establish hydrophobic interaction in the space of the pocket that would accommodate the glucose present in the lactose, avoiding the undesired transglycosylation reaction (Fig. (12)). Thus, this study demonstrated that the incorporation of bulky substituents at C-9 position provided inhibitors with specificity and dramatically slows reactivation of the enzyme by transglycosylation.

The discovery of 3-fluorosialyl fluoride and analogues, which are the most advanced inhibitors of TcTS to date, designed as a classic bioisostere of sialic acid, illustrate the success of the use of classic bioisosteric relationship between the hydrogen and fluorine atoms [26].

To further evaluate the potential of TcTS inhibitors as anti-T. cruzi drugs it is necessary to evaluate their effects in the animal model of Chagas' disease in order to check the in vivo effects of TcTS inactivation. Since this enzyme is important for parasite invasion of mammalian cells and possibly to protection of $T$. cruzi against immune mechanisms [27], being an immunodominant antigen on the parasite' surface, the inhibition of TcTS may facilitate the elimination of the parasite by the host.

\section{POISONING THE PARASITE' REDOX SYSTEM: IN- HIBITORS OF TRYPANOTHIONE REDUCTASE}

It is well-documented that Trypanothiones, of the family of flavin-containing disulfide oxido-reductases NADPH-

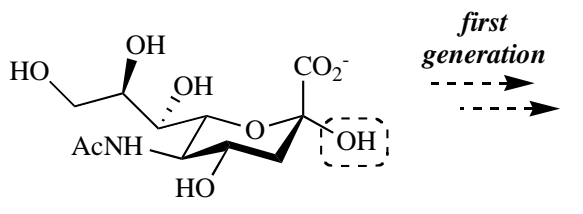

sialic acid

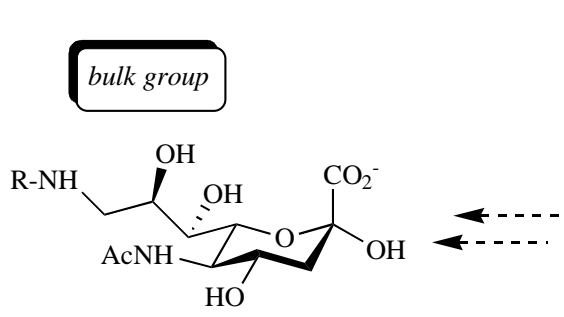

9-arylamide-3-fluorosialic acid

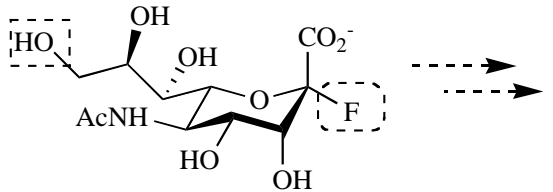

3-hydroxylfluorine sialic acid

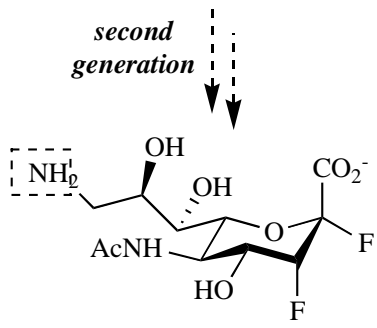

9-amino-3-fluorosialic acid

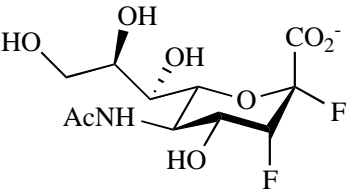

3-fluorosialyl fluoride

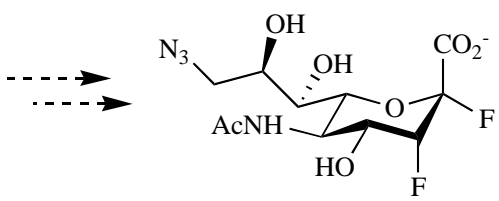

9-azide-3-fluorosialic acid

Fig. (11) Design of sialic acid mimetics, exploring Fluorosialyl as prototype.
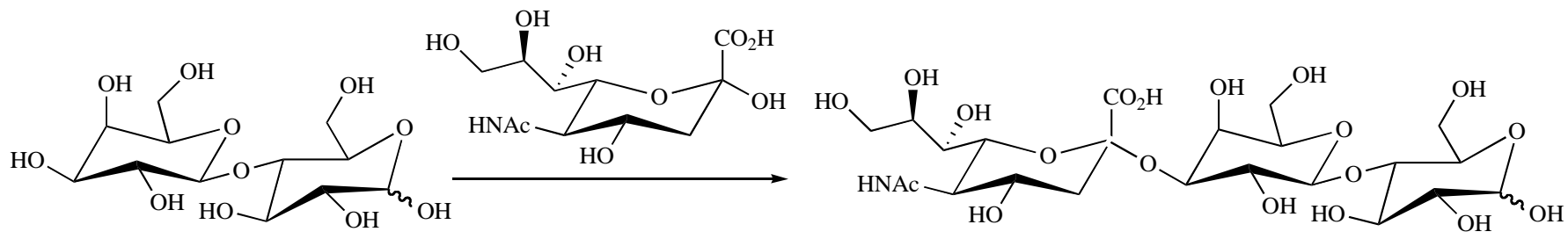

Fig. (12) Pathway of transglycosylation reaction during TSTc reactivation. 
dependent, comprise an essential enzymatic system for the redox metabolism. The co-factor trypanothione $\left[N^{1}, N^{8}\right.$-bis $(-$ glutathionyl)spermidine] is present as reduced $\left[\mathrm{T}(\mathrm{SH})_{2}\right]$ or oxidized $\left[\mathrm{T}(\mathrm{S})_{2}\right]$ forms (Fig. (13)) on the parasite [28]. The TRTc maintain trypanothione in its reduced form (i.e., trypanothione disulfide to dihydrotrypanothione) and thus contributes to decrease the levels of free radicals, as well as of hydroperoxides $I$ superperoxides species. Therefore, the TRTc system protects parasite cells by removing potential oxidizing species generated by aerobic metabolism, chemotherapy agents or by host macrophages [29]. This mechanism is analogous to the mammalian redox metabolism, which uses glutathione reductase (GR) as a protection system. However, there is a remarkable specificity between TRTc and GR in relation to their substrate that may allow the design of drugs that affect selectively the TRTc system.

Often, the strategies of drug design targeting the TRTc system have been developed in two ways: (i) planning TRTc inactivators based on subversive substrates, betraying the redox system [30]; (ii) planning drugs that act through the formation of free radicals or oxidizing species with depletion of trypanothione [31].

The first class of anti-T. cruzi compounds with remarkable action on the depletion of trypanothione were the nitroheterocyclics, including Nifurtimox and Megazol. Nitroheterocyclics act by formation of reactive oxygen species in T. cruzi cells, which are responsible for inducing oxidative stress, followed by depletion of trypanothione, as revisited by Maya and co-workers [32]. Approximately 1500 nitrocompounds were recorded as anti-T. cruzi agents, but only $2 \%$ were shown to inhibit the parasite in nanomolar range and with demonstrated low cytotoxicity against mammalian cells [33]. Thus, this information about structures containing nitro groups constitute an important background on the medicinal chemistry of parasitic drugs, since in the majority of the cases these drugs have poor selectivity for parasites and also act in the mammalian counterparts. Because the depletion of trypanothione is more difficult due it needs to generate free radical, the drug development of inhibitors that inactivate the TRTc (involved in trypanothione metabolism) appears to be an approach more feasible.

During the HTS project aiming to find new TRTc inhibitors based on natural sources, Lunarine, a macrocyclic spermidine alkaloid isolated from Lunaria biomis, was discovered as a competitive inhibitor and the kinetics studies indicated non-covalent binding to TR followed by covalent binding to the reduced form of TR. Thus, it seemed as an ideal characteristic for TRTc inactivators [34]. However, tests in T. cruzi cell cultures revealed values of $\mathrm{IC}_{50}=65 \mu \mathrm{M}$ against trypomastigotes, indicating a need to structural optimization on the Lunarine (Fig. (14)).

Considering this data, Hamilton and co-workers applied extensive SAR studies, in order to identify the minimal framework necessary to obtain strong TRTc inactivation and<smiles>[NH3+]C(CCC(=O)NC(CSSCC(NC(=O)CCC([NH3+])C(=O)O)C(=O)NCC(=O)NCCCNCCCCNCC(=O)NCC(=O)O)C(=O)NCC(=O)O)C(=O)O</smiles>

$\left[\mathrm{T}(\mathrm{S})_{2}\right.$<smiles>CC(=O)C([NH3+])CCC(=O)NC(CS)C(=O)NCC(=O)NCCCNCCCCNC(=O)CNC(=O)C(CS)NC(=O)CCC([NH3+])C(=O)O</smiles>

$\left[\mathrm{T}(\mathrm{SH})_{2}\right.$

Fig. (13) Pathway of oxi-reduction of trypanothione catalyses by TRTc.

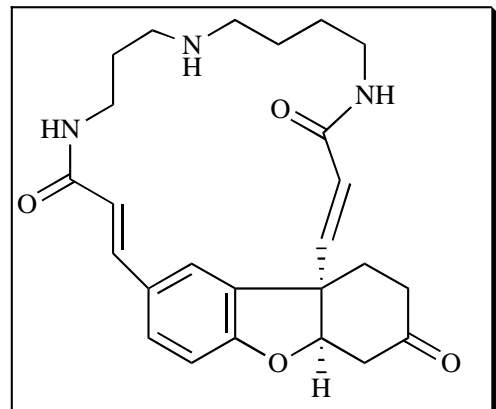

Lunarine, 'hit' from natural sources inhibitor of TRTc enzyme

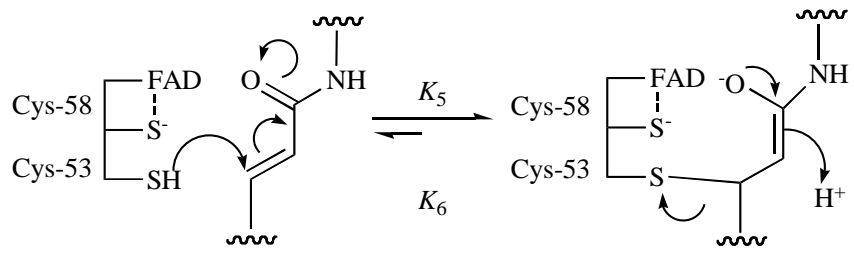

proposal mechanism of time-dependent inativation by Lunarine

Fig. (14) Structure of natural product Lunarine and its mechanism of action. 
antiproliferation action, exploring principles of molecular simplification [35]. Some encouraging results were obtained, and it was possible to observe the optimization of the enzymatic kinetic profile for the non-cyclic Lunarine analogue when compared to the prototype (Fig. (15)). This compound is an analogue presenting the non-cyclic nature as the only structural difference, suggesting that compounds less conformationally constrained can have a new inhibitory profile.

Exploring the early discovery of tricyclic inhibitors that are specific for TRTc over GR, such as chlorpromazine, chlomipramine, amitryptyline and trifluperazine [36-38] and based on studies of molecular modeling (docking), Parveen and co-workers decided to investigate the importance of conformational factors and the presence of charge for some phenothiazine quaternary analogues of open-chain [39]. In fact, the quaternization of the nitrogen atom on the 2-amino-4- chlorophenyl phenyl sulfide analogues (TR inhibition with $K i$ between 5.3-14.2 $\mu \mathrm{M}$ ) resulted in improvement of potency and enzymatic profile when compared to series of quaternary alkylammonium phenothiazine (TR inhibition with $K \mathrm{i} 66 \mu \mathrm{M}$ ), probably by positive charge onto nitrogen and linked with aryl substituents (Fig. (16)). By contrast, the $N$ acyl-2-amino- 4-chlorophenyl sulfides were two-fold less potent as TRTc inhibitors. Is well recognized that structures containing charge implies in changes on electronic distribution of atoms, with consequently alternation in terms of pharmacodynamic properties [40]. In fact, the docking pose showed orientations and energies by involvement of the Zsite hydrophobic pocket of TRTc structure, as well as ionic interactions for the cationic nitrogen with residues Glu-466' or Glu-467'. In addition, during the in vitro assay against $T$. cruzi trypomastigotes, it was possible to observe the remarkable differences of potency between the tricyclic and non-

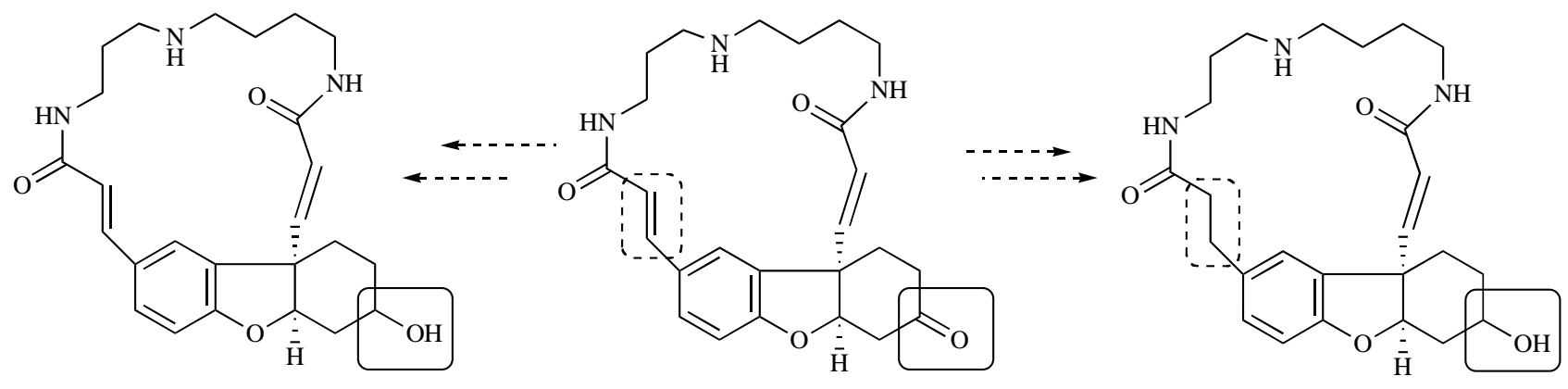

Lunarinol

Lunarine

Tetrahydrolunarinol

SARs:

- Double bonds are important; -Cyclohexanone is crucial;

- Reduction of carbonyl carbon is deleterious for activity; -Macrocyclic nature is importante but not crucial;

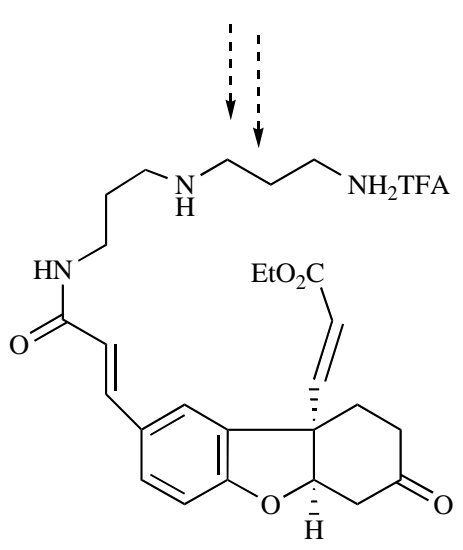

non-cyclic Lunarine

Fig. (15) Representative Lunarine analogues, designed using the concepts of simplification molecular.<smiles>[R]C(=O)Nc1cc(Cl)ccc1Sc1ccccc1</smiles>

2-amino-4-chlorophenylphenylsulfides

phenothiazine

$N$-acyl-2-amine-4-chlorophenylphenylsulfides

Fig. (16) Phenothiazines (centre) converted to acyclic bioisosteres, explored as TRTc inhibitors. 
cyclic series, being the non-cyclic series the most potent, with good values of $\mathrm{IC}_{50}$, and thus attractive for further structural exploration.

During another HTS project enabling Thioredoxin Reductase (TRxR) inhibitors developed by researchers from Pfizer, three unsatured Mannich base were found as $P$. falciparum thioredoxin reductase inhibitors [41]. The human selenoprotein TRxR is involved in antioxidant defense and DNA synthesis and, more importantly, the catalytic mechanism of TrxR is similar to that of glutathione reductase [42]. From the target point of view, Lee and co-workers decided to explore unsaturated Mannich base as scaffold to develop new TRTc inhibitors (Fig. (17)) [43].

This work culminated in the development of compound 5-(2'chlorophenyl)-3-oxo-4-pentenyl, that showed higher irreversible inactivation $\left(\mathrm{IC}_{50}=2.0 \mu \mathrm{M}\right)$ than unsaturated Mannich base containing alkylammonium $\left(\mathrm{IC}_{50}=5.0 \mu \mathrm{M}\right)$, as well as distinct kinetic profile while assayed with enzyme. Furthermore, this strategy of molecular modification on the Mannich base enables the antiproliferation activity against $T$. cruzi $\left(\mathrm{IC}_{50}=12.5 \mu \mathrm{M}\right.$ in amastigotes $)$ and $T$. brucei $\left(\mathrm{IC}_{50}=\right.$ $1.9 \mu \mathrm{M}$, bloodstream form) while mammalian cytotoxicity was very low $\left(\mathrm{IC}_{50}=1230 \mu \mathrm{M}\right)$. It is interesting that the cyclic bioisoster from 5-(2'chlorophenyl)-3-oxo-4-pentenyl was inefficient to inhibit the enzyme, illustrating a spectacular example in which the conformational restriction of double bond resulted in total loss of molecular recognition by enzyme.

Another class of TRTc inhibitors is constituted by acridine derivatives. In 1984, quinacrine (also called mepacrine), a functionality acridine derivative, was found as an potent inhibitor of $T$. cruzi proliferation in vitro [44], and the crystal structure of the TRTc-quinacrine complex was solved [45]. Consequently, the investigation of this bioactive framework to antitrypanosomal agents allowed reasonable SARs, as summarized in Fig. (18).

The innovative work of Bonse and co-workers [46] and Saravanamuthu and co-workers [47] directed to generate structural modifications of quinacrine allowed the finding of relevant SAR data. Using the strategy of molecular simplification it was observed that 9-amino-6-chloro-2-methoxyacridine constitutes the minimal structural core to irreversibly inactivate the TRTc. Attaching an alkylamino chain, as well as the homologation of chain, improved the potency. In contrast, the bioisosteric replacement of nitrogen by sulfur atom implies in changes of kinetic enzymatic pattern and potency, resulting in a mixed-type inhibition (competitive and noncompetitive) by 9-thioacridine when all other acridine derivatives, including quinacrine, show only competitive inhibition. Later on, with the crystallographic analysis of the TRTc-quinacrine mustard complex, it was possible to identify which of the two ligands (quinacrine mustard) Interact with the same active site of the enzyme, whereas one acridine subunit interact with the other acridine subunit by $\pi$ approximation (Fig. (19)) [47].

The replacement of the alkylamino moiety by sulfonamide or urea was also considered as strategic structural modification on the quinacrine (Fig. (20)). The enzyme assays showed that both sulfonamide and urea contribute to increase in tenfold the potency against TRTc. In general, however, the loss of selectivity was also observed, since the activity of Glutathione Reductase (mammalian counterpart) was remarkably inhibited. The employment of this strategy probably resulted in important alterations of the donor/ acceptor H-bonding sites, as well as in the conformational orientations of the respective pharmacophoric points (sulfonamide or urea), creating a remarkable differentiation in the molecular recognition pattern of compounds onto TRTc enzyme. Finally, in vitro assays against $T$. cruzi amastigotes for this series showed only weak to moderate inhibition [48].

From this survey, it is seems that a useful practice for identifying new trypanocidal compounds is to monitor hit compounds previously found by screening campaign on the thioredoxin reductase system, as exemplified with Mannich base. Another interesting set of structure are acridines. The degree of trypanocidal activity, via TRTc irreversibly inactivation, and both encouraging physicochemical parameters and low cytotoxicity make of the acridines "privileged structures" [49] for identifying further hit compounds.

\section{BIOIONORGANICS: NEW OPPORTUNITY TO AN- TIPARASITIC MEDICINAL CHEMISTRY}

The transition metal complexes have progressed steadily over the last two decades, from a handful of curious exam-

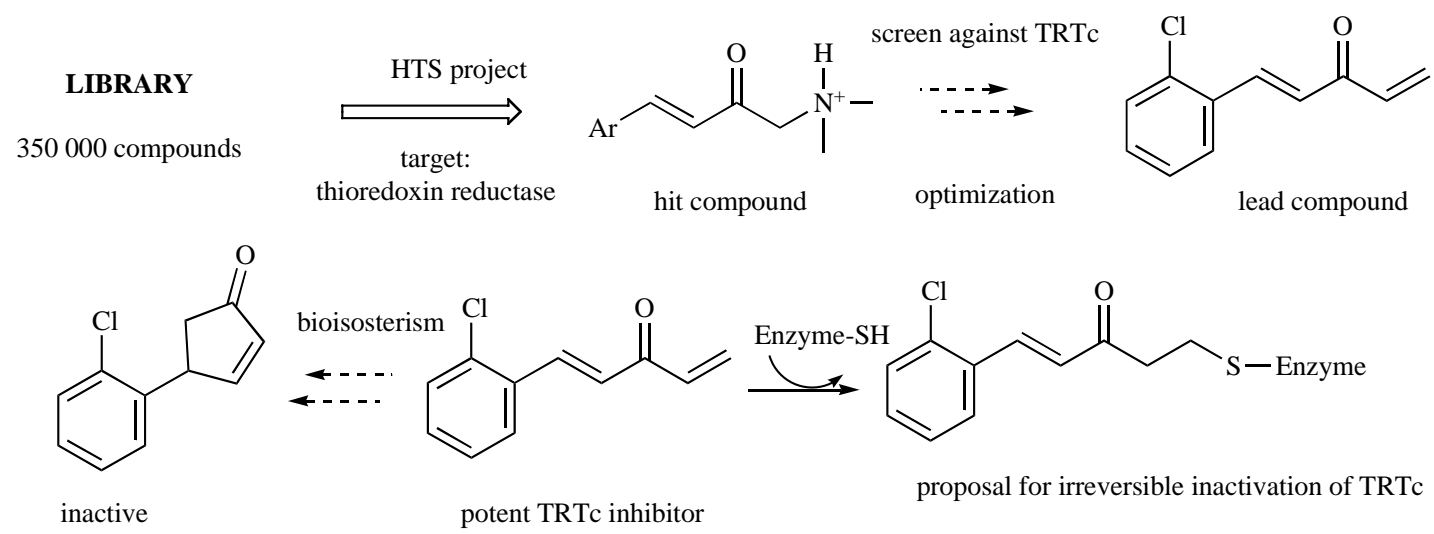

Fig. (17) TRTc inactivators discovered by HTS initiative. 


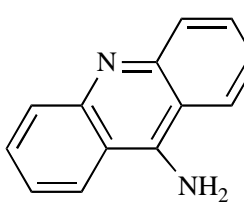

aminoacridine $K \mathrm{i}=38 \mu \mathrm{M}$

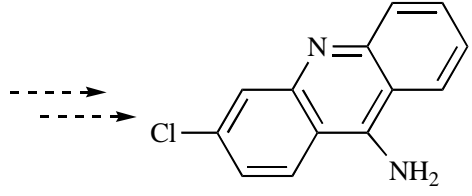

9-amino-6-chloroacridine

$K \mathrm{i}=43 \mu \mathrm{M}$

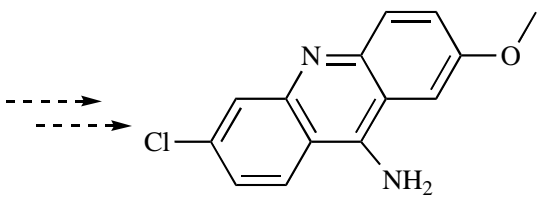

9-amino-6-chloro-2-methoxyacridine

$K \mathrm{i}=07 \mu \mathrm{M}$<smiles>CCCCCCC(CCCN1CC2CC3CC2CC3C1)Nc1c2ccc(Cl)cc2nc2ccc(OC)cc12</smiles>

quinacrine

$\mathrm{Ki}=19 \mu \mathrm{M}$<smiles>I[V]I</smiles>

homologation

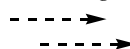

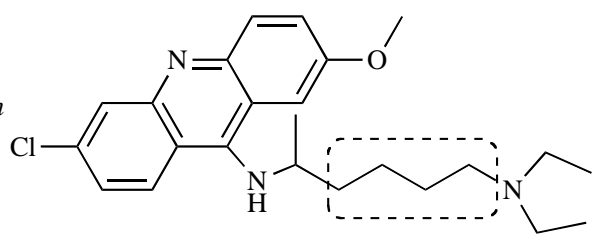

quinacrine analogue

$\mathrm{Ki}=5.5 \mu \mathrm{M}$

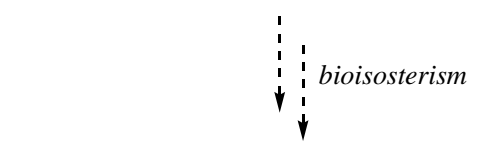

$\downarrow$

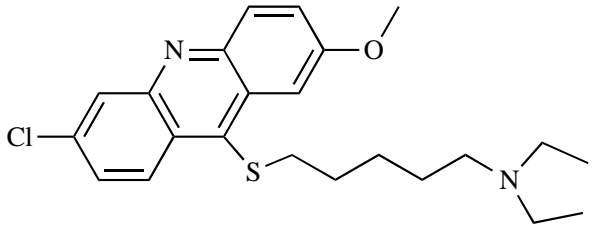

thioquinacrine

$\mathrm{Ki}=21 \mu \mathrm{M}$

Fig. (18) Acridine subunit explored as antitrypanosomal agents via TRTc inhibition and their binding affinities (Ki).

ples to a well established application on the world-wild chemotherapy. Transition metals adopt different oxidation states, which allows for change of conformation and reactivity and also to participate in biological redox chemistry. Additionally, the ability of metal complexes to undergo ligand exchange reactions is recognized as an important way to interact with biomacromolecules by coordination [50]. The DNA structure was the first recognized target by metal complexes but, more recently, other targets that interact with metal complexes were also discovered [51]. With the detailed mode of action of metal complexes understood, many other strategies have appeared to develop more potent chemotherapy agents. In this context, an expressive number of studies have evidenced that metal complexes inhibit the class of cysteine-proteases [52, 53], opening an attractive opportunity for the medicinal chemistry of antiparasitic drugs.

From the literature survey of metal complexes as antitrypanosomal agents, it is possible point out two strategies of drug design: complexation of bioactive molecules (more often called ligands), since that remarkable change of pharmacodynamic and pharmacokinetic properties is observed between free ligand and it metal complex; or complexation to non-bioactive ligands with desired chemical properties (volume, electronic distribution, inductive or mesomeric effects when fitting).

Due to the early work on metal-drug based compounds focused on Platinum, Lowe and co-workers [54] decided to start an extensive investigation of Platinum complexes, using the strategy " $3+1$ ", containing terpyridines as tridentate

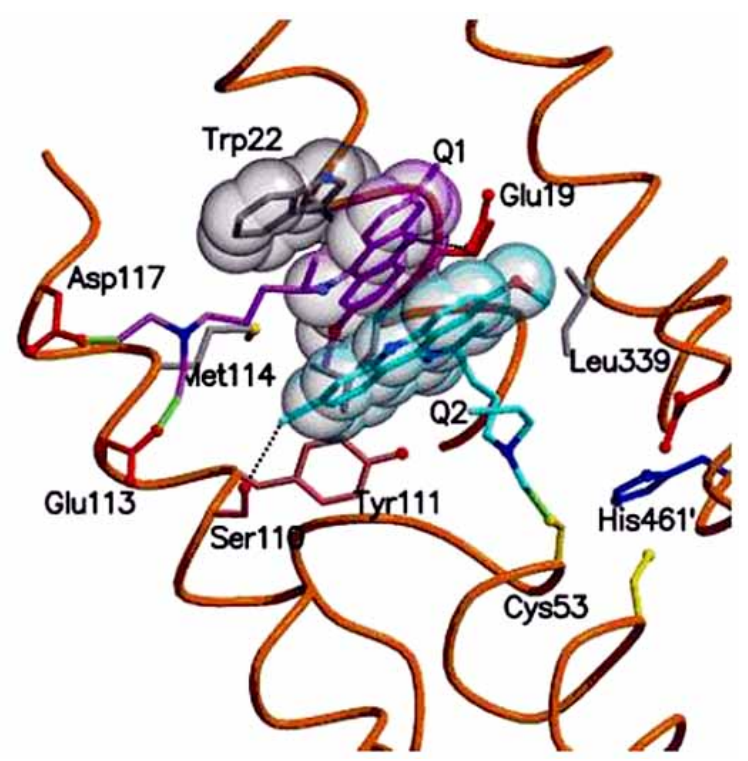

Fig. (19) Stereoview of the active site of TRTc with bound quinacrine mustard (Q1 and Q2) [after ref. 47]. 


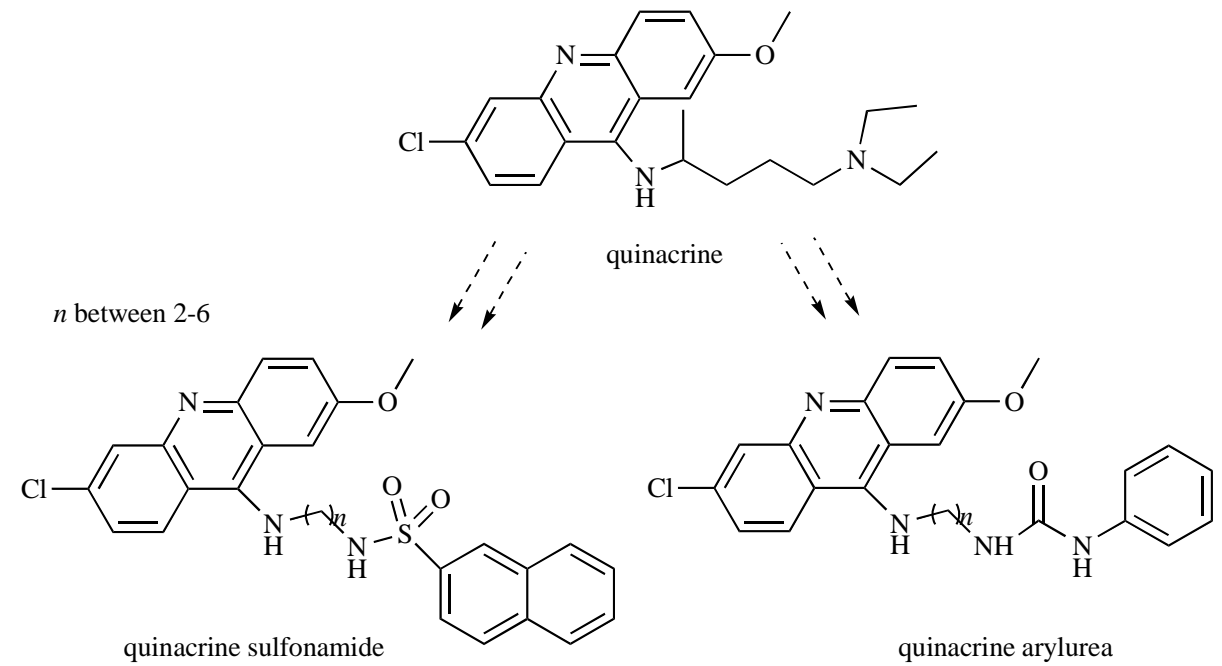

Fig. (20) Exploring bioisosteric relationships of Quinacrine.<smiles></smiles>

$\mathrm{R}: p-\mathrm{Br}-\mathrm{C}_{6} \mathrm{H}_{4}, 78.2 \%$ inhibition at $1 \mu \mathrm{M}$

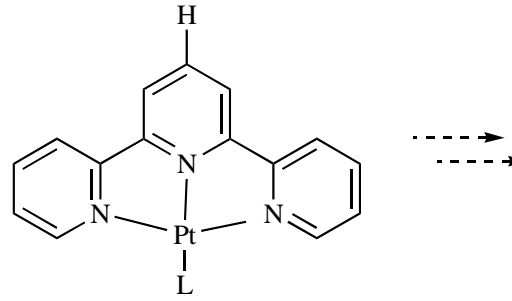

$\mathrm{L}: \mathrm{NH}_{3}, \quad 72 \%$ inhibition at $1 \mu \mathrm{M}$

$\mathrm{L}: \mathrm{H}_{2} \mathrm{O}$, inactive at $1 \mu \mathrm{M}$

$\mathrm{L}: \mathrm{Cl}, \quad 52 \%$ inhibition at $1 \mu \mathrm{M}$

$\mathrm{L}: \mathrm{MeCN}$, inactive at $1 \mu \mathrm{M}$<smiles></smiles>

$72 \%$ inhibition at $1 \mu \mathrm{M}$ but more cytotoxic of them

Fig. (21) Design of Platinum complexes, using "3+1" mixed-ligand set.

ligand and modifying only the monodentate ligand (Fig. (21)). With this approach it was possible to obtain a large series of Platinum complexes, and thus, to establish a robust SAR. The most potent compound of this series was able to inhibit the proliferation of amastigotes in the range of $1 \mu \mathrm{M}$, being also non-cytotoxic when tested on macrophages. Thus, this strategy proved to enable the discovery of anti-T. cruzi agents.

Considering the biological profile of Ketoconazole and Clotrimazole, that act as sterol biosynthesis inhibitors, Navarro and co-workers explored the complexation these two drugs with a set of transition metals, including Ruthenium, Cupper, Gold, Platinum and Rhodium [55-57]. As summarized in Fig. (22), a significant increase of antiproliferative activity against epimastigotes of $T$. cruzi was observed, with inhibition around $1.0 \mu \mathrm{M}$. This probably accounts by a typical ligand exchange between chlorine and water, activating the complexes for covalent modification of the parasite target. Although the observed potency was similar when Ketoconazole or Clotrimazole were used, the oxidation state of the metal was shown to have an important role.
The group of medicinal chemistry leaded by Prof. Cerecetto has achieved success during the complexation of transition metals, such as Platinum, Cupper, Ruthenium, Palladium, and Vanadium, with several bioactive ligands. During structural modifications on the quinoxaline scaffold aiming to discover potent trypanocidal agents were conducted, but no success was obtained [58]. Since Vanadium complexes have attracted more attention due to their relative stability, low cost and an ongoing interest for their use in the treatment of cancer, antimicrobial and insulin mimetics properties [59], hence, this same group decided to explore the complexation of a series of 3-aminoquinoxaline-2-carbonitriles with Vanadium, as strategy to optimization of the solubility of quinoxalines in lipophilic media, and consequently to enhance the bioavailability (Fig. (23)).

On the one hand, the antiproliferative tests against epimastigote forms of $T$. cruzi evidenced that the complexation to Vanadium of the 3-aminoquinoxaline-2-carbonitriles results in remarkable improvement of trypanocidal activity. On the one other hand, both ligands and Vanadium precursor were inactive. Theoretical and experimental values of lipo- 


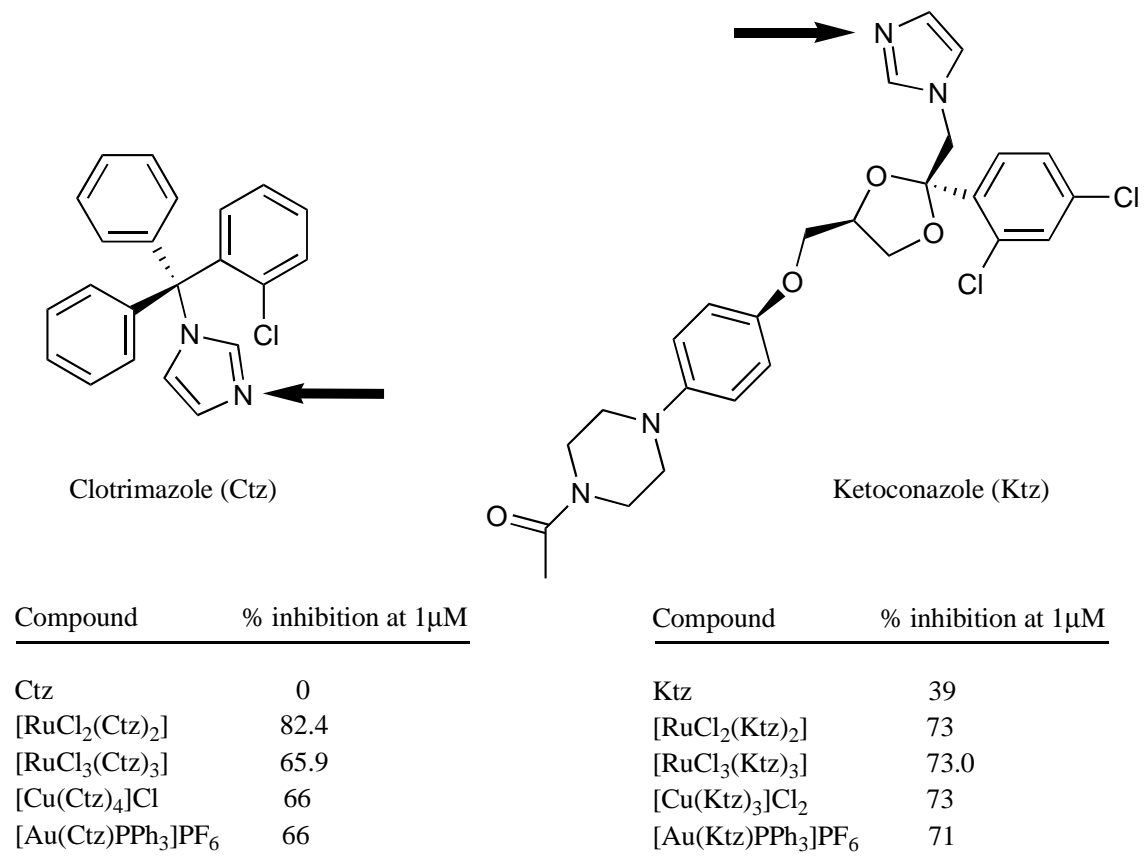

Fig. (22) Set of Ktz and Ctz complexes, explored as anti-T. cruzi agents. Arrow indicates the domain of complexation with metal.

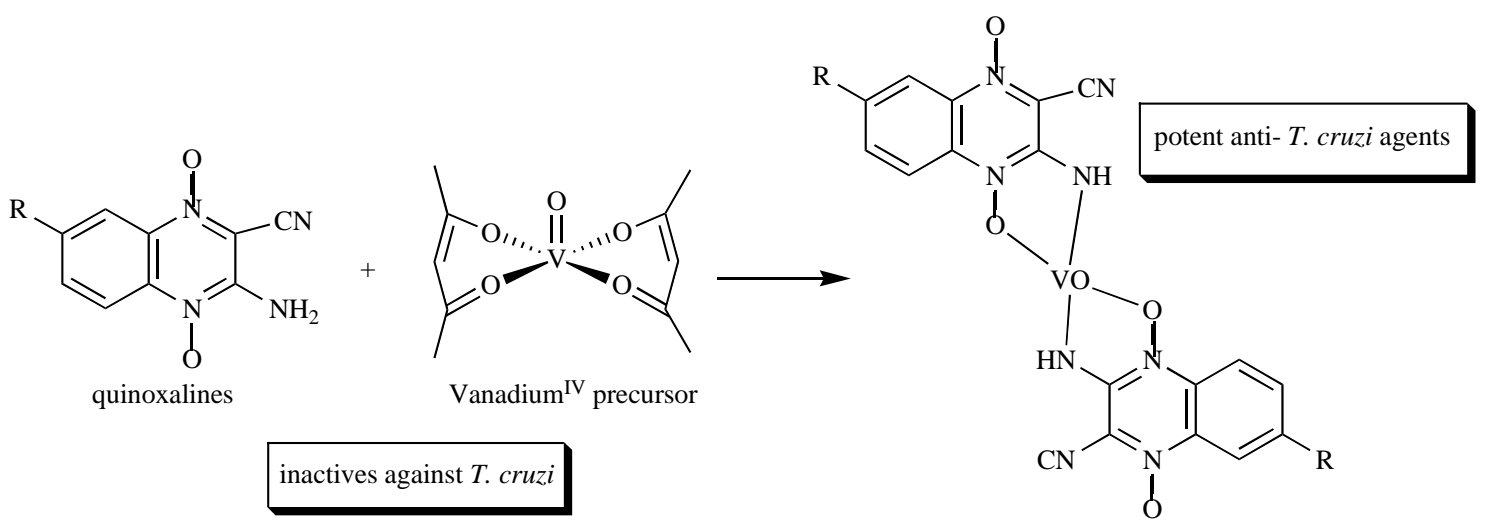

R: $\mathrm{H}, \mathrm{CH}_{3}, \mathrm{OCH}_{3}, \mathrm{~F} . \mathrm{Cl}, \mathrm{Br}, \mathrm{CF}_{3}$

Fig. (23) Complexation of Vanadium with quinoxalines to improve the antitrypanosomal activity.

philicity suggested that the improvement of anti-T. cruzi properties occurs probably by the consequence of increased lipophilicity character typical for the metal complexes when compared to free ligands [60].

In 2004 a Uruguayan patent developed by same group claimed the preparation and use as anti-T. cruzi agents of novel Platinum complexes [61]. Based on well-established antitrypanosomal activity of thiosemicarbazones, its complexation with Platinum (II) was considered as a potential strategy for improving the potency of the ligands (Fig. (24)). In fact, one of these Platinum complexes was a potent agent, being fivefold more potent than Bdz and Nfx, although data about cytotoxicity against mammalian cells were not available for this complex. In addition, studies of its mechanism of action suggested the production of free radical and oxygen consumption on $T$. cruzi epimastigotes, with consequently action on the DNA structure of the parasite.

Finally, it is worthwhile to mention that, different from the Platinum or Palladium complexes early described, complexes of Ruthenium and Cupper containing similar ligands were found to have poor trypanocidal activity $[62,63]$. The authors described that some undesired physicochemical properties for these complexes of $\mathrm{Ru}$ and $\mathrm{Cu}$, such as high hydrophilicity as well as high protein binding capacity, were probably the reasons to the low activity observed.

Contrasting the metal complexes as antitrypanosomal activity that mainly are related to target the DNA as early described, four studies were published more recently showing metal complexes as inhibitors of TCC, TRTc, NADHfumarate reductase of $T$. cruzi and NO-donors. 


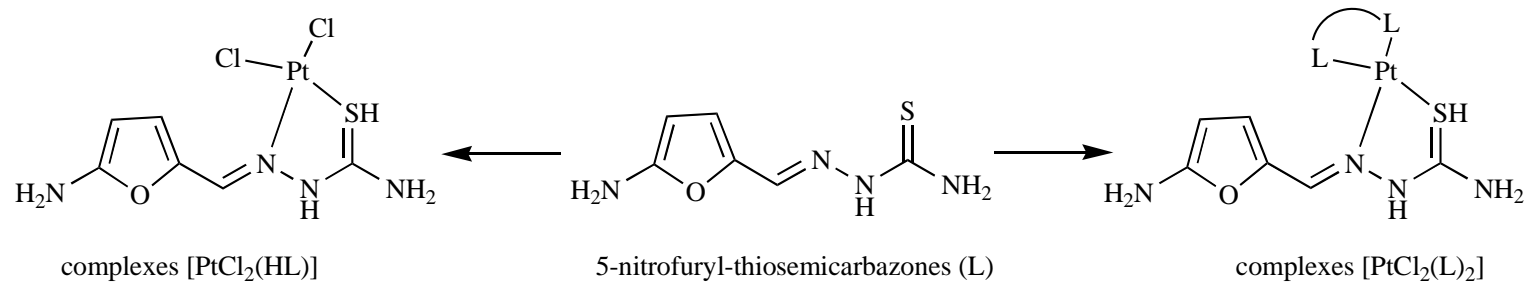

$$
\begin{aligned}
& \text { Magnitude of activity: } \\
& {\left[\mathrm{PtCl}_{2}(\mathrm{~L})_{2}\right]>\mathrm{Bdz}>>\left[\mathrm{PtCl}_{2}(\mathrm{HL})\right]} \\
& \text { For substituent }\left(\mathrm{R}_{1}\right) \text {, activity is: } \\
& \mathrm{CH}_{2} \mathrm{CH}_{3} \gg \mathrm{CH}_{3}>\mathrm{Ph}=\mathrm{H}
\end{aligned}
$$

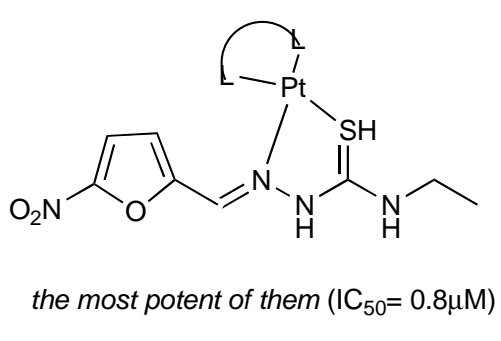

Fig. (24) Nitrofurylthiosemicarbazones and their Platinum complexes targeting DNA.

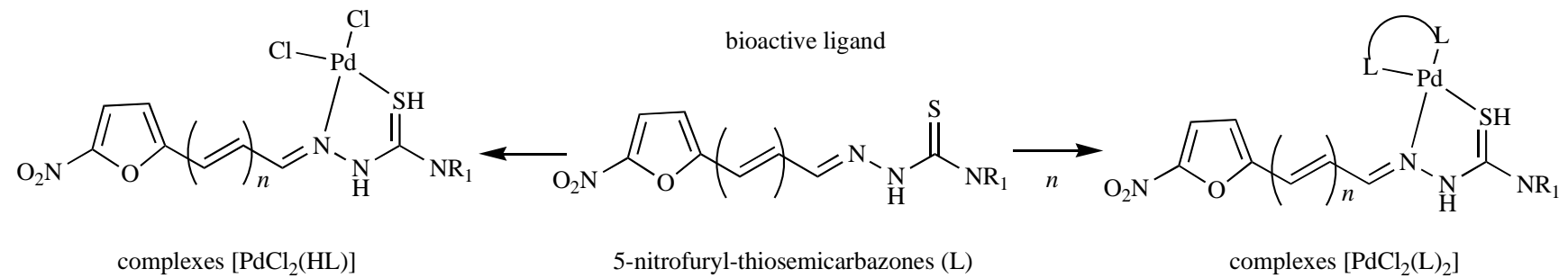

$n: 0$ or $1 ; \mathrm{R}_{1}=\mathrm{H}, \mathrm{CH}_{3}, \mathrm{CH}_{2} \mathrm{CH}_{3}$ or $\mathrm{C}_{6} \mathrm{H}_{5}$

Fig. (25) Palladium complexes with Nitrofurylthiosemicarbazones targeting TRTc instead of DNA.

Complexes of Palladium with 5-nitrofurylthiosemicarbazones were explored by Otero and co-workers [64], aiming the optimization of the trypanocidal activity for these ligands (Fig. (25)). In general, it was observed that Pd complexes containing two 5-nitrofurylthiosemicarbazones as ligands were more potent as trypanocidal agents than Pd complexes with only one ligand. Also, most of Pd complexes were remarkably more potent than free ligands, with $\mathrm{IC}_{50}$ values lower than Nifurtimox. More important, Pd complexes exerted the trypanocidal activity due to the inhibition of the TRTc activity, in contrast with the free ligands, suggesting that these Pd complexes target TRTc rather than DNA structure. With data of electrochemistry and electronic spin resonance studies it was possible to postulate that the irreversible inhibitory activity on the TRTc for these complexes probably occurs by a redox metabolism. Although the ligands possess a nitro group that can generate oxygen radical species, it appears that Pd is of critical importance to the mechanism of TRTc inactivation.

T. cruzi NADH-fumarate reductase is crucial for the parasite energetic metabolism, catalysing the conversion of fumarate to succinate, using NADH as co-factor [65]. The complexation of Platinum or Palladium with pyridine-2-thiol $\mathrm{N}$-oxide (that is well-known NADH fumarate reductase inhibitor) was found to be a successful strategy to improve the enzymatic inhibition, allowing the generation of potent anti-
T. cruzi agents with in vitro activity in nanomolar range against epimastigote forms of T. cruzi [66]. Full tests of in vitro cytotoxicity activity revealed a good selectivity index for Platinum complexes and moderate for Palladium complexes (Fig. (26)). Finally, and more interestingly, it was observed that the two complexes did not inhibit neither the TRTc activity nor interacted with DNA, and thus should be a useful starting point to address drug development targeting NADH-fumarate reductase system.
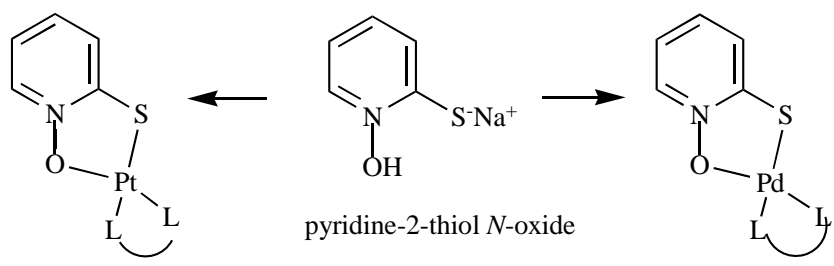

$\mathrm{IC}_{50}=200 \mathrm{nM}$

$\mathrm{IC}_{50}=190 \mathrm{nM}$

$\mathrm{IC}_{50}=67 \mathrm{nM}$

the most advanced inhibitors of NADH-fumarate reductase to date

Fig. (26) Fumarate-reductase NADH inhibitors based on metal complexes. Data of $\mathrm{IC}_{50}$ corresponds to assay in parasite culture.

Bearing in mind that nitric oxide (NO)-dependent lysis of T. cruzi by murine macrophages occurs, and therefore NO- 
donors may confer a possibility of drug design [67], Silva and co-workers [68] studied the in vitro and in vivo trypanocidal profiles of eight Ruthenium complexes, planned as source of NO. In fact, it was firmly established that seven of these $\mathrm{Ru}$ complexes inhibited both epimastigote and trypomastigote forms of $T$. cruzi in superior potency when compared to Bdz, gentian violet and sodium nitroprusside, a NOdonor analogue. A comparative analysis of time-dependency inhibition revealed that $\mathrm{Ru}$ complexes were able to reduce the parasite levels after $1 \mathrm{~h}$ of treatment, while the reference drugs did not reduce. Detailed studies of reduction potential (expressed as the $\mathrm{Ru}^{\mathrm{II}} \mathrm{NO}^{+} \backslash \mathrm{Ru}^{\mathrm{II}} \mathrm{NO}^{0}$ ) and the specific rate constant for NO release $\left(K_{\mathrm{NO}}\right)$ were conducted by authors, in order to rationalize the biological results, and was observed a general trend that the $\mathrm{Ru}$ complexes more easily reduced (i.e., values of reduction potential more positive) have the most potent trypanocidal activities.

Two of these $\mathrm{Ru}$ complexes, trans- $\left[\mathrm{Ru}(\mathrm{NO})(\mathrm{NH})_{3} \mathrm{imN}\right]$ $\left(\mathrm{BF}_{4}\right)_{3}$ and trans-[Ru(NO)(NH)$)_{4}$ isn $]\left(\mathrm{BF}_{4}\right)_{3}$ were elected to in vivo assay and showed efficacy to eliminate extracellular and intracellular forms of the $\mathrm{Y}$ strain of parasite in mice treated i.p. with $100 \mathrm{nmol} . \mathrm{kg}^{-1}$. day ${ }^{-1}$ during 15 consecutive days, when at same dose, mice treated with $\mathrm{Bdz}$ did not survive. Besides, histopathological analysis evidenced a decrease in myocarditis in mice treated with $\left[\mathrm{Ru}(\mathrm{NO})(\mathrm{NH})_{3} \mathrm{imN}\right]\left(\mathrm{BF}_{4}\right)_{3}$ complex.

Considering the previous knowledge that Rhenium complexes are endowed with potent inhibitory effects against the CP cathepsin B [69], Fricker and coworkers [70] tested a diverse set of metal complexes against two parasitic $\mathrm{CP}, \mathrm{cpB}$ of Leishmania major and TCC, aiming to find metal complexes to inhibit preferentially the parasitic CP of than the cathepsin B. Using the strategy of " $3+1$ " mixed-ligand set as framework (Fig. (27)), was observed that Gold complexes inhibited the cathepsin B in nanomolar range, when Oxorhenium and Palladium complexes were more selective to inhibit the parasitic CP. Additionally and more promising, complexes of Oxorhenium and Palladium shown to have excellent selectivity vs related proteases, such as serine protease chymotrypsin. The antiproliferative activity also was carried out, while two Oxorhenium complexes were potent inhibitors on $T$. cruzi life cycle, however at concentration very near to toward cytotoxicity in host cells.

Analyzing the SARs, it is seems that the binding mode of metal complexes are driven by nature of ligands, because ligands can establish polar interactions and also shape matching with the binding site, although ligands can sometimes also bind purely through hydrophobic contacts and still allowed differences of potency. Besides, absence of selectivity in the enzymatic assay was observed for the Oxorhenium complexes containing chlorine as ligands, indicating that another way to address the biological activity occur it, probably by feasible exchange of the chlorine ligands with water in biological media [51]. Overall, therefore, this work represents a important advance in metal-based drugs underlying anti-T. cruzi agents since activities were verified to both enzyme and cell cultures.

Despite the broad-based efforts devoted to developing metal complexes as antiparasitic drugs, important questions related to the choice of ligand set around the metal centre and safety profile remain unanswered. Except for few examples on the literature, the assessment of the toxicity on mammalian cells for these metal complexes is not available.

\section{TARGETING ON THE T. CRUZI CRUZAIN (TCC): THE 'PIGGYBACK' STRATEGY}

TCC is a member of the papain family of cysteine proteases (CP), with structure and properties very similar to the mammalian enzymes cathepsin L and cathepsin B [71]. TCC is capable of degrading components of the extracellular matrix, and is involved on the replication and nutrition of the parasite. In addition, this enzyme has been implicated in the virulence of parasite because TCC catalyses the proteolysis of kininogen, producing the Lys-bradykinin proinflammatory

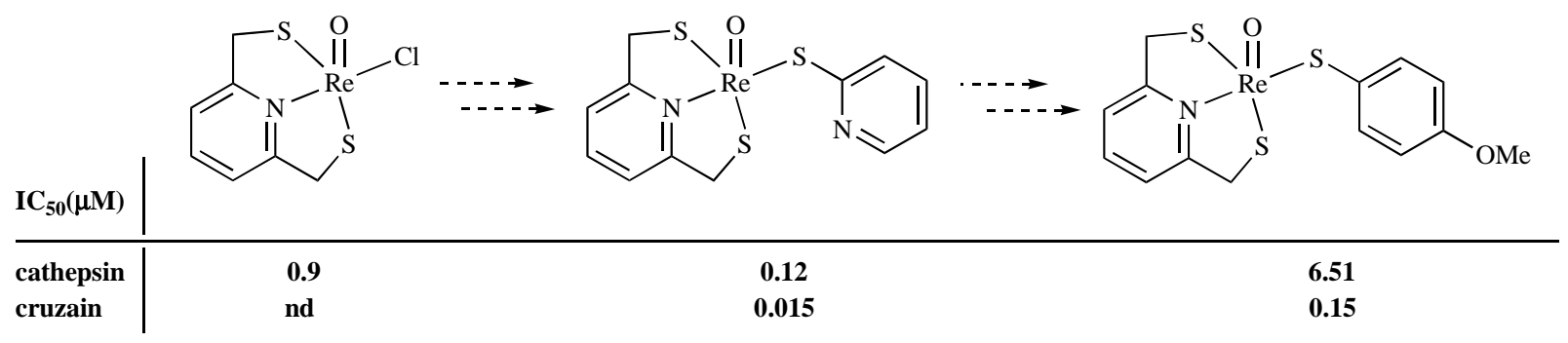

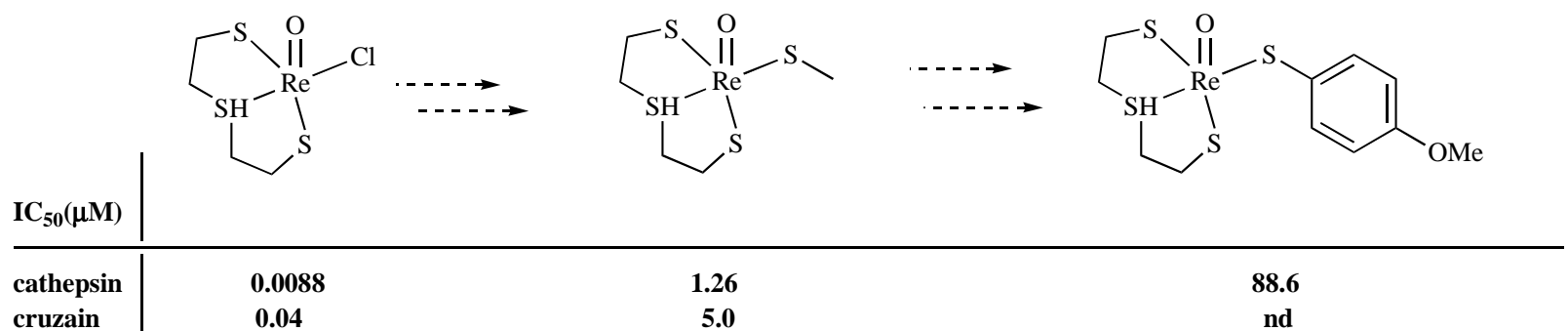

Fig. (27) Evolution of CP inhibitors based on metal complexes. 
peptide, which seems to be of crucial importance to the invasion of trypomastigotes into host cells [72]. These data indicate that TCC constitutes an attractive drug target.

Due to the great interest of pharmaceutical companies in the development of cathepsin B inhibitors as cancer drug therapy [69], the 'piggy-back' strategy [73], in which a molecular target present in parasites is pursued by using compounds designed for other indications increasing the ratio (or speed) of drug discovery and consequently reducing the costs, has been employed in the case of drug design for parasitic CP inhibitors.

The main inactivation mechanisms occur with the participation of cysteine and histidine residues located in opposite sides on the active site of TCC. These two residues form a stable thiolate-imidazolium ion pair, and then the thiolate intermediate is able to promote a nucleophilic attack on the carbonyl carbon of the amide bound (such as in endogenous peptides or inhibitors). This feature potentially provides a means to design inhibitors that covalently interact with the enzyme [74].
Considering the key structure of compounds containing amide groups, the first generation of structural templates screened as TCC inhibitors was composed by small dipeptides and by peptidomimetics. A set of molecular modifications were employed in these templates, exploring functional groups of recognized reactivity to interact with thiolate intermediate present on active site of $\mathrm{CP}$, such as epoxyketones, diazomethylketones and vinyl sulfones (Fig. (28)). Except for dipeptidyl containing vinyl sulfone moiety, in general most dipeptidyl derivatives showed irreversible inhibition with values of $K i$ on enzyme in micromolar range, and had low selectivity vs a related protease (serine protease chymotrypsin), with a consequent high toxicity against mammalian cells [75-77].

However, it is important to point out that the vinyl sulfone subunit has been explored during the fragment-based drug discovery for new non-peptidyl inhibitors of the TCC [78]. One TCC inhibitor based on vinyl sulfone peptide cured the infection of $T$. cruzi in an immunodeficient mouse model by intraperitoneal administration, even in the absence

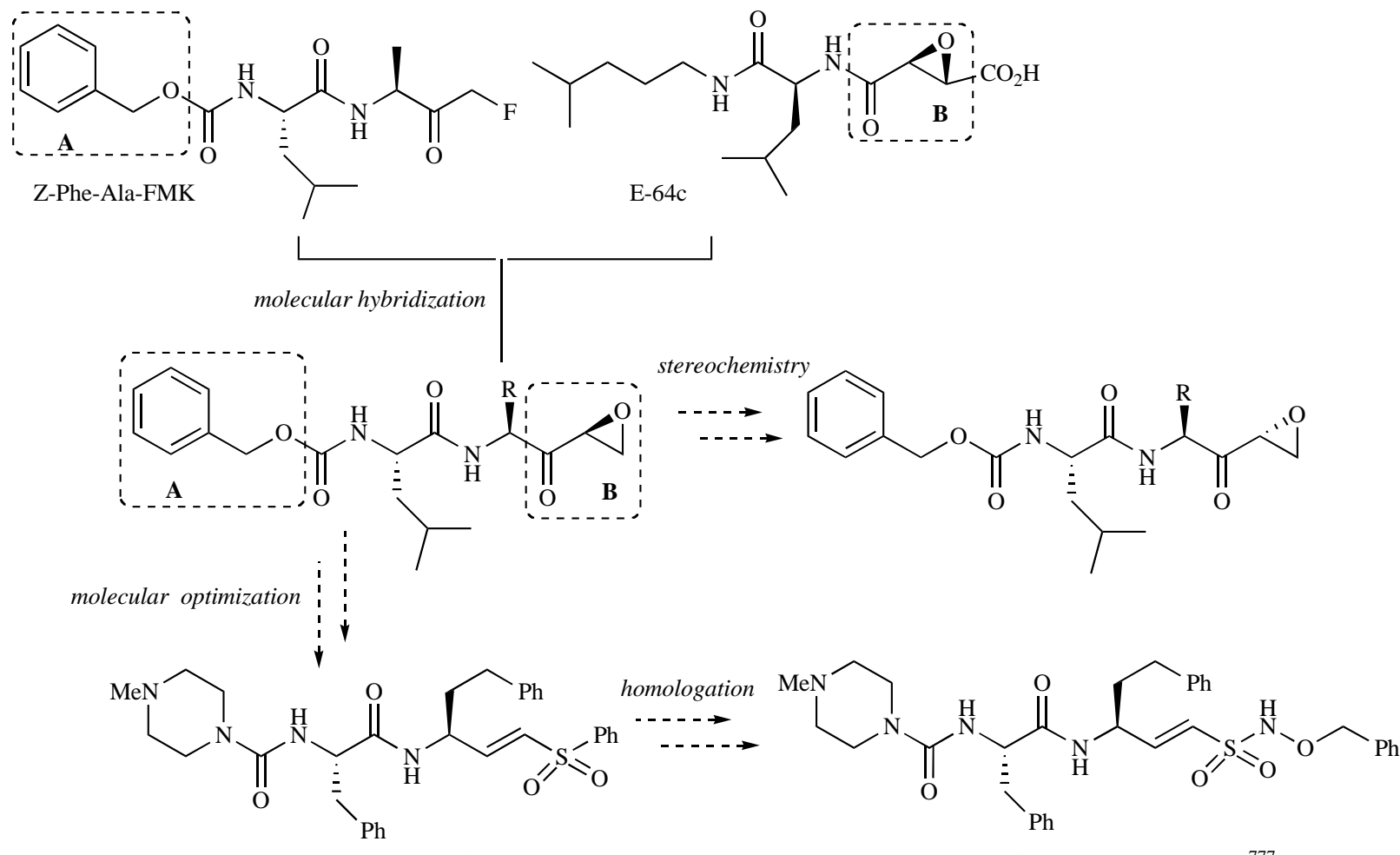

K-777: potent TCC inhibitor, but inactive against cell cultures

100fold more potent than $\mathrm{K}^{-777}$ active against cells culture at $10 \mathrm{mM}$

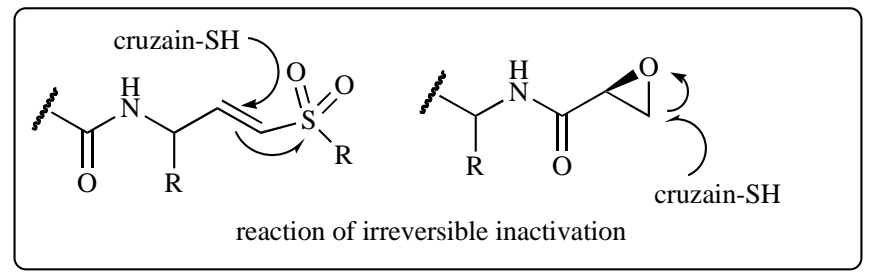

Fig. (28) Design concept of TCC irreversible inhibitors exploring peptidyl derivatives. Data of $\mathrm{IC}_{50}$ corresponds to assay with the pure enzyme. 
of a functioning adaptive immune response [79], indicating that TCC inhibitors affect the pathology appropriately.

The replacement of a very flexible scaffold (such as a peptide backbone) by a more rigid central scaffold can improve significantly the binding affinity, avoiding the lack of selectivity, and also the overall ADME properties. Thus, several $N$-acyl-hydrazones have been explored as potential nonpeptidic TCC inhibit due to the structural analogy between the last one and amide group, but with potential additional benefit of lower reactivity and stability (that are capable of forming more specific interactions with the TCC target and, hence, delivering higher selectivity) [80-82]. One hit compound (ZLIII43A) was identified as having excellent selectivity vs related proteases (serine protease) and a desired pharmacokinetic profile. Some SARs were established, yielding values of $\mathrm{IC}_{50}$ between $0.9-2 \mu \mathrm{M}$ against TCC (Fig. (29)). However, after being assayed in in vivo protocols, none of the lead compounds emerged as promising candidates to anti-T. cruzi drugs.

During an HTS campaign of parasitic CP inhibitors, Du and co-workers [83] found 10 hits with $\mathrm{IC}_{50}$ values below 10 $\mu \mathrm{M}$ against cruzain, and two of this hits also inhibited the replication of $T$. cruzi amastigotes. Docking studies carried out by the same authors highlighted their binding mode on cruzain, while the energy scores obtained for the ten hit compounds were very similar, suggesting that these hit compounds occupy the same pocket in the enzyme. By structural analysis of these hits, some common structural domains were observed, especially the urea, thiourea and sulfonamide subunits, allowing the establishment of a set of SARs, as well as the molecular modification, as briefly depicted in (Fig. (30)). Urea D16 was the best hit compound and, despite the efforts to permit the structural optimization through the isosteric replacement and also the generation of congeneric series, it was not possible to identify other urea derivatives more potent of than D16, which remained as the most active derivative.

When compared to the $N$-acyl-hydrazones scaffold, urea and thiourea have better hydrogen bonding capabilities, are more stable and presented more potent than $\mathrm{N}$-acylhydrazones while assayed against TCC. These observations were used as basis for further studies of non-peptidic TCC inhibitors, exploring scaffolds structurally related to urea and thiourea. This resulted in the election of semicarbazones, thiosemicarbazones and their cyclic analogues as a potential class of reversible inhibitors of parasitic CPs. Diverse thiosemicarbazones were evaluated as CP inhibitors (including also rhodesain of $T$. brucei and falcipain-2 of Plasmodium falciparum), exploring the design of congeneric series and some of the principles of bioisosterism, molecular repetition, and homologation, thus creating a robust set of SARs, as summarized in Fig. (31). Initially, by exploiting the congeneric series of aryl-thiosemicarbazones with several substituents in aromatic ring, Du and co-workers [84] identified twelve potent $\mathrm{TCC}$ inhibitors that presented $\mathrm{IC}_{50}$ values below $200 \mathrm{nM}$.

Among the active aryl-thiosemicarbazones, the hit compound 3-(bromopropiophenone)thiosemicarbazone (1i) was able to inhibit the TCC at concentration of $100 \mathrm{nM}$ in a timedependent manner, evidencing the reversible inactivation on enzyme. Remarkable differences in potency during the congeneric series were observed, probably reflecting the importance of the steric factor in the binding into the enzyme. Interestingly, several pyrazoline derivatives seem to be more conformational restricted analogues than aryl-thiosemicarbazones, were as potent as aryl-thiosemicarbazones against

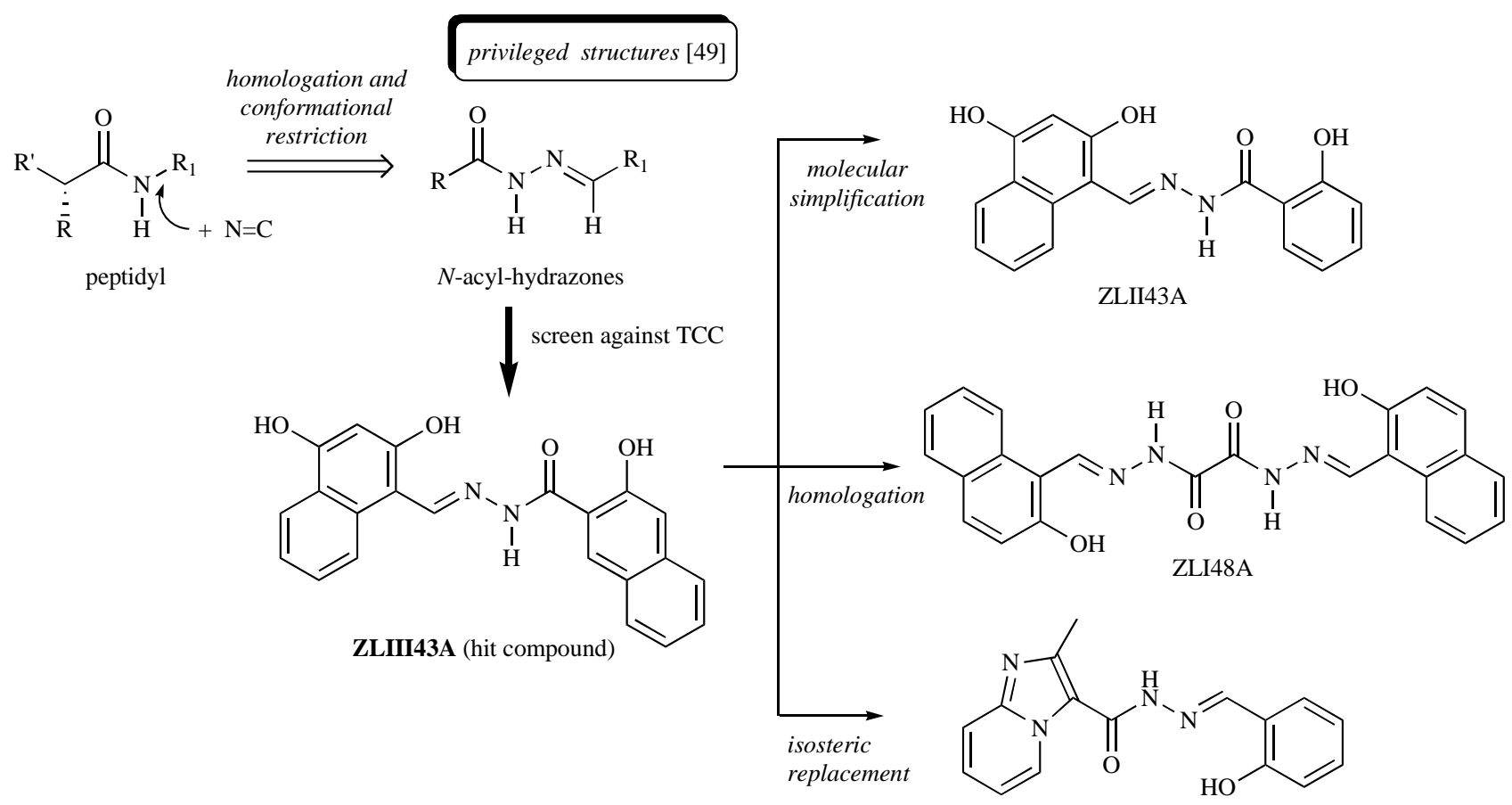

LASSBio-334

Fig. (29) Some SARs employed for $N$-acyl-hydrazones as TCC inhibitors. 


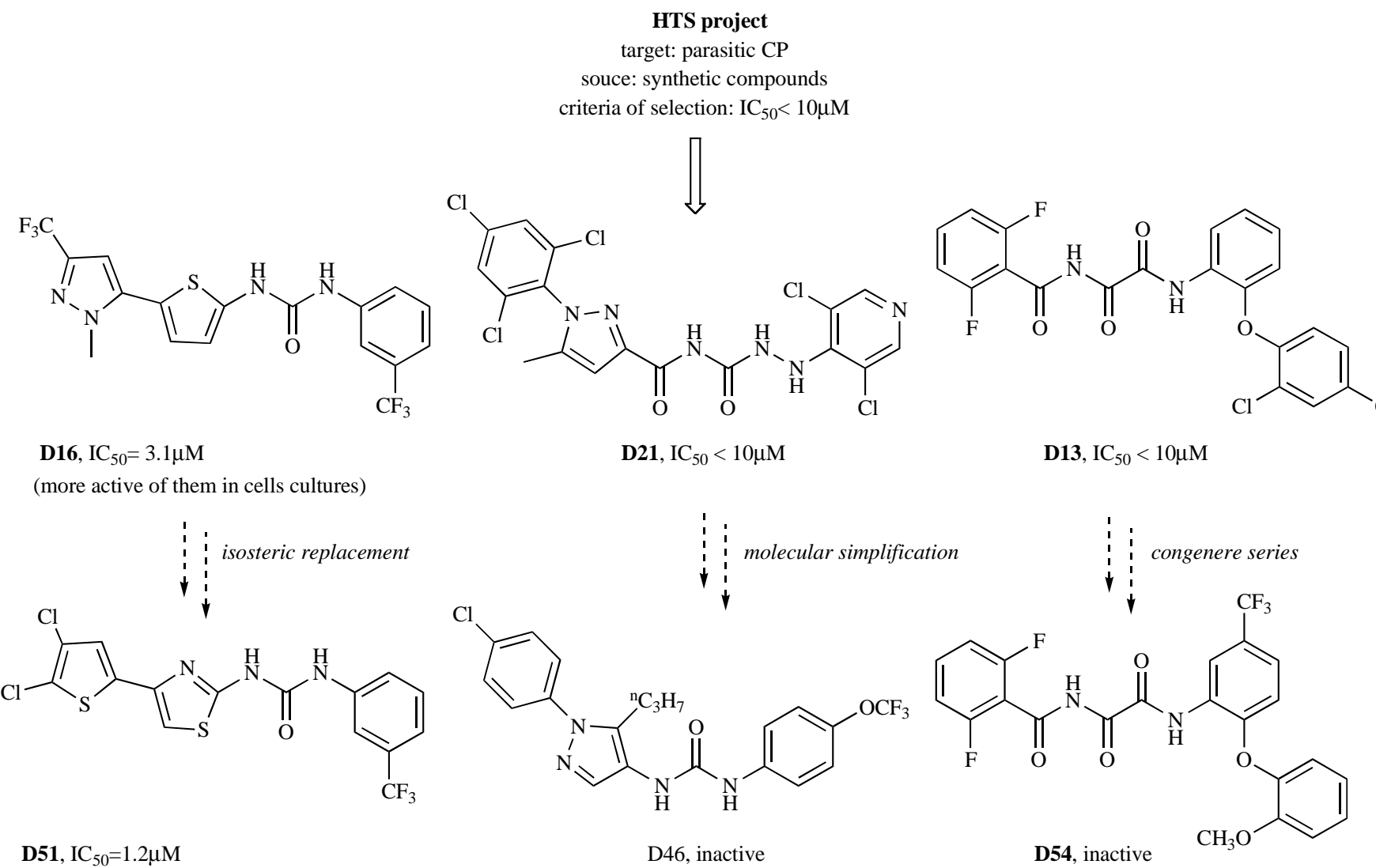

(lesser active in cell cultures than D16)

Fig. (30) Design concept of TCC irreversible inhibitors exploring peptidyl derivatives. Data of $\mathrm{IC}_{50}$ corresponds to assay with the pure enzyme.

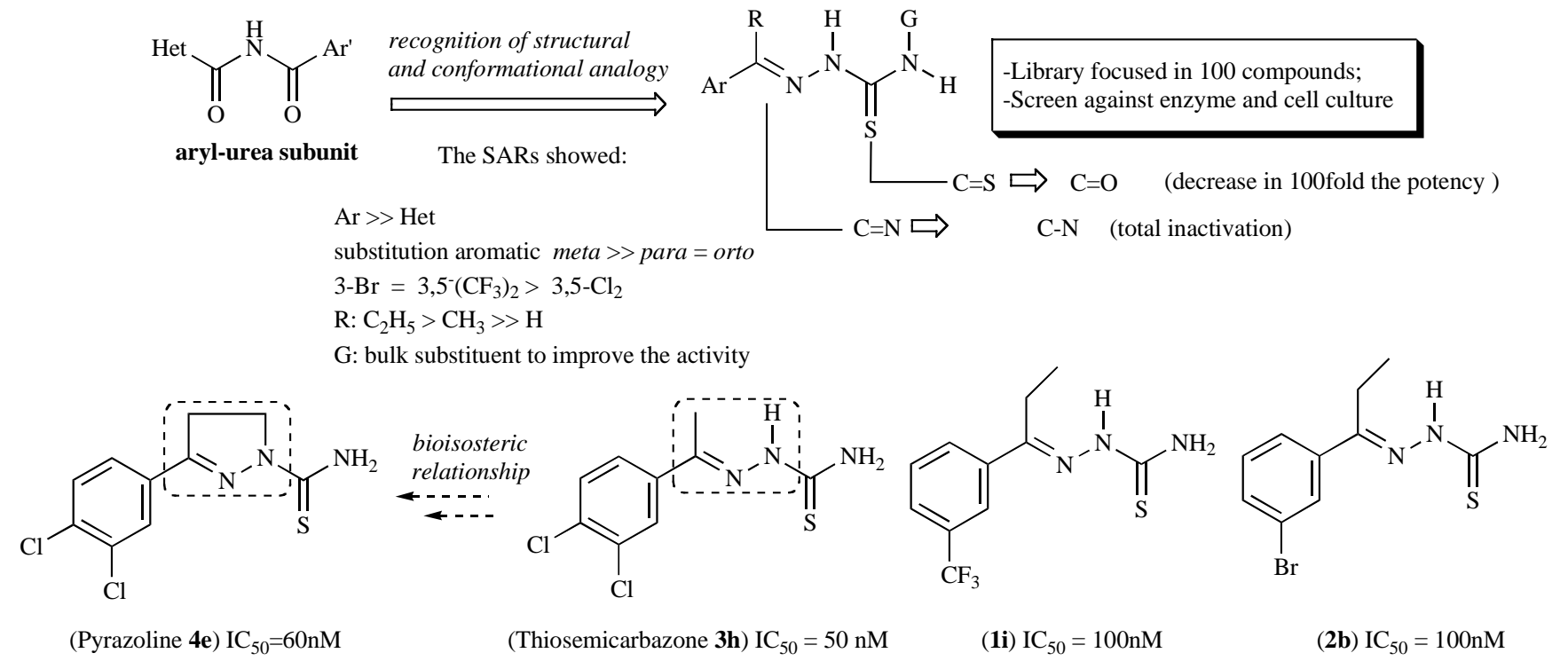

Fig. (31) SARs of TCC reversible inhibitors exploring thiosemicarbazone scaffold. Data of $\mathrm{IC}_{50}$ corresponds to assay with the pure enzyme.

TCC and had similar activity against the parasite in vitro, being a typical example of classic bioisosteric relationship between cyclic and non-cyclic scaffolds, although the arylthiosemicarbazones still remained as the most attractive one because it is easier to derivatize and synthetically tractable. During this work the molecular docking analysis with TCC permitted to highlight their binding pattern and showed that the aryl group occupies a deep pocket (S2), while the thiose- 
micarbazone is oriented very close to His- 159 and Cys-25, which are key residues on the binding site of the enzyme. In a more detailed analysis it was also evidenced that for hit (1i) the ethyl group attached in methylene (C5) to occupy and fit into the pocket (S1), putatively affecting the docked geometry. T. cruzi-infected cells treated with hit (1i) at $10 \mu \mathrm{M}$ survived 41 days in culture, compared to 6 days for the untreated controls, thus emerging as a prototype to anti-T. cruzi drug candidate.

This successful example of TCC inhibitor has stimulated the efforts to find new compounds structurally related with (1i), such as molecular repetition [85], the attachment of bulk substituent to occupy the pocket (S1) of enzyme [86] and also the replacement of aryl group by rigid skeletons [87] (Fig. (32)).

Our research group has applied the bioisosterism strategy to obtain new anti-chagasic scaffolds via inhibition of TCC, designed as non-classic bioisosteres of thiosemicarbazones. A set of cyclic and non-cyclic compounds were studied, resulting in a congeneric series of new aryl-thiazolyl-hydrazones that, after pharmacological evaluation against $T$. cruzi cultures, showed to be potent inhibitors of parasite replication (Fig. (33)). The most active compound of aryl-thiazolylhydrazone series in our work presented an $\mathrm{IC}_{50}=0.9 \mu \mathrm{M}$ against the epimastigote form of $T$. cruzi at non cytotoxic concentration for mammalian cell $[88,89]$.

ref.[85]<smiles>C/C(=N\NC(N)=S)c1ccc(Nc2ccccc2)cc1</smiles><smiles>C/C(=N/NC(N)=S)N/N=C(\C)c1cccc(C(N)=S)c1</smiles>

$\mathrm{IC}_{50}=20 \mu \mathrm{M}$

\section{CONCLUDING REMARKS}

Recent advances in the understanding of drug targets and their function on T. cruzi, combined with the use of modern tools of medicinal chemistry and allied with remarkable improvement in the quality and diversity of compound libraries, has contributed to the finding of potent and validated prototypes, candidates to anti- $T$. cruzi drugs. Many studies in the literature do not report the values of cytotoxicity of the compounds tested against $T$. cruzi. Because toxicity is a major cause of failure in drug development, the determination of cytotoxicity can allow the determination of the selectivity index (expressed as the $\mathrm{IC}_{50}$ (mammalian cells) $/ \mathrm{IC}_{50}$ (parasite) ratio, helpful for the election of the best drug candidates and avoiding many setbacks.

Remarkably, the discovery of new generations of TcTS and TCC inhibitors is quickly advancing by the extensive use of those modern tools. In chemical terms, the natural products chemistry and application of HTS works are representative sources to provide new sophisticated lead structures of usefulness on the parasitic medicinal chemistry.

Despite the large and expanding number of potential antiparasite targets, the assessment of the most promising should be carefully carried out to validate them as candidates before "commitment to long-term studies on development of specific inhibitors". Thus, it appears to be appropriate to select three hot points on medicinal chemistry of anti- $T$.

less potent

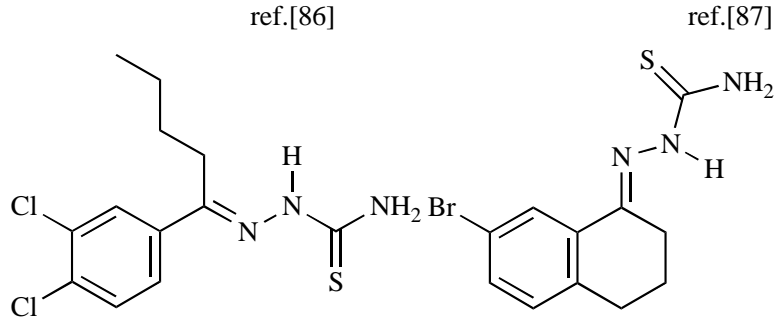

ref.[87]

Fig. (32) Evolution of thiosemicarbazone scaffold as TCC reversible inhibitors. Data of $\mathrm{IC}_{50}$ corresponds to assay with the pure enzyme.

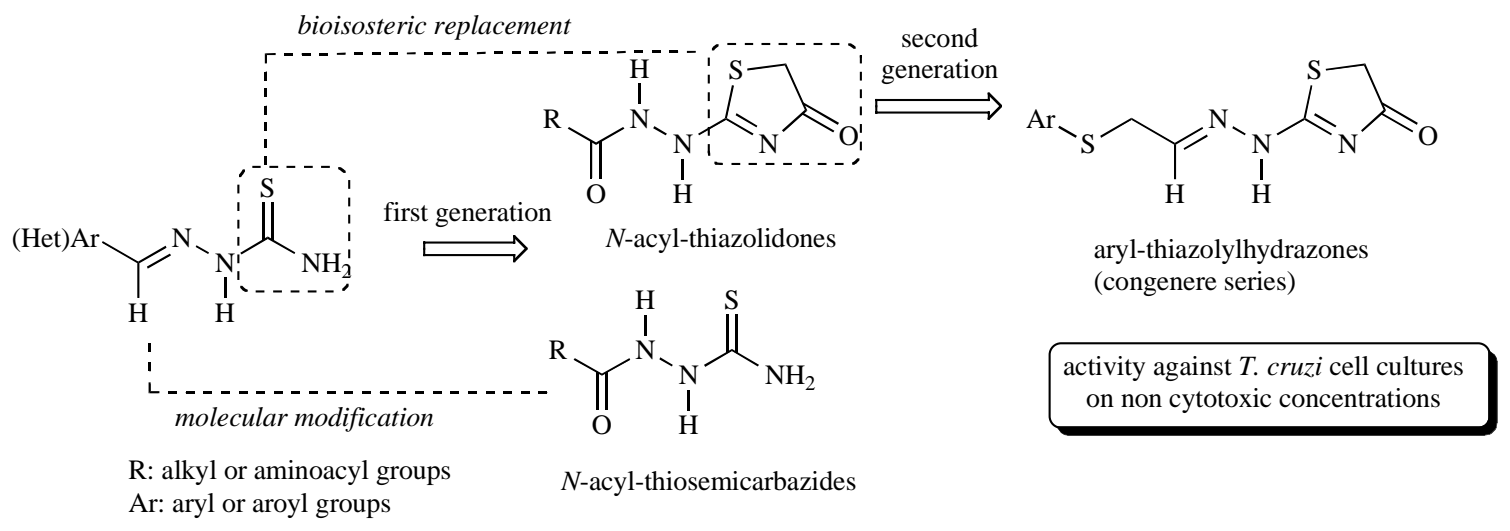

Fig. (33) Design concept of TCC inhibitors exploring bioisosteric relationship with thiosemicarbazone scaffold. 
cruzi drugs as exciting possibilities for investigation: (i) exploring new TcTS inhibitors based on non-sugar scaffolds; (ii) identification of targets for metal complexes; and (iii) screening thioredoxin reductase system inhibitors of recognized activity and of NO-donors against the parasite.

\section{ACKNOWLEDGEMENTS}

Work in our laboratories was funded by $\mathrm{CNPq}$, RENORBIO, IMSEAR, Institutos do Milênio, FAPESB, and FACEPE grant APQ-0123-4.03/08 (to A.C.L.L. and D.R.M.M.). M.B.P.S and R.R.S. are senior researchers for CNPq. D.R.M.M. acknowledges support from CNPq by providing $\mathrm{PhD}$ fellowship. A.C.L.L. thanks Prof. E. J. Barreiro (UFRJ) for providing some references.

\section{ABBREVIATIONS}

Bdz $=$ Benznidazole
CP $=$ Cysteine Protease
GR $=$ Hlutathione Reductase
HTS $=$ High Throughput Screening
Nfx $=$ Structure-Activity Relationship
SAR $=$ Trypanothione Reductase of T. cruzi
TRTc $=$ T. cruzi Cruzain
TCC $=$ T. cruzi Trans-sialidase

\section{REFERENCES}

[1] Coura, J.R. (2007) Mem. Inst. Oswaldo. Cruz, 102 (Suppl. I), 113122.

[2] Docampo, R.; Moreno, S.N.J. 1984) In: Free Radicals in Biology, Vol. 6, pp. 243-288

[3] Patrice-Trouiller, P.; Olliaro, P.; Torreele, E.; Orbinski, J.; Laing, R. and Ford, N. (2002) Lancet, 359, 2188-2195.

[4] Lemos, T.L.G.; Monte, F.J.Q.; Santos, A.K.L.; Fonseca, A.M.; Santos, H.S.; Oliveira, M.F.; Costa, S.M.O.; Pessoa, O.D.L. and Braz, R. (2008) Nat. Prod. Res., 21, 529-550.

[5] Nwaka, S. and Ridley, R.G. (2003) Nat. Rev. Drug Discov., 2, $919-$ 928.

[6] Cerecetto, H. and González, M. (2002) Curr. Top Med. Chem., 2, 1185-1213.

[7] Brenk, R.; Schipani, A.; James, D.; Krasowski, A.; Gilbert, I.H.; Frearson, J. and Wyatt, P.G. (2007) ChemMedChem, 2, 435-444.

[8] Tse-Dinh, Y.C. (2007) Infect. Disord. Drug Targets, 7, 3-9.

[9] Kinnamon, K.E.; Poon, B.T.; Hanson, W.A.; and Waits, V.B. (1998) Am. J. Trop. Med. Hyg., 58, 804-806.

[10] Bodley, A.L. and Shapiro, T.A. (1995) Proc. Natl. Acad. Sci. USA., 92, 3726-3730.

[11] Riou, G.F., Gabillot, M., Douc-Rassy, S., Kayser, A. and Barrois, M. (1983) Eur. J. Biochem., 134, 479-484.

[12] Hammond, D.J.; Cover, B. and Gutteridge, W.E. (1984) Trans. $R$. Soc. Trop. Med. Hyg., 78, 1-95.

[13] Fouce, R.B., Redondo, C.M., Pertejo, Y.P., Gonzalez, R.D. and Reguera, R.M. (2006) Drug Discov. Today, 11, 733-740.

[14] Martinez, R. and Garcia, L.C. (2005) Curr. Med. Chem., 12, 127151.

[15] Girault, S.; Grellier, P.; Berecibar, A.; Maes, L.; Mouray, E.; Lemire, P.; Debreu, M.A.; Davioud-Charvet, E. and Sergheraert, C. (2000) J. Med. Chem., 43, 2646-2654.

[16] Caffrey, C.R.; Steverding, D.; Swenerton, R.K.; Kelly, B.; Walshe, D.; Debnath, A.; Zhou, Y.; Doyle, P.S.; Fafarman, A.T.; Zorn, J.A.; Land, K.M.; Beauchene, J.; Schreiber, K.; Moll, H.; Ponte-Sucre, A.; Schirmeister, T.; Saravanamuthu, A.; Fairlamb, A.H.; Cohen,
F.E.; McKerrow, J.H.; Weisman, J.L. and May, B.C.H. (2007) Antimicrob. Agents Chemother., 51, 2164-2172.

[17] Neres, J.; Bryce, R.A. and Douglas, K.T. (2008) Drug Discov. Today, 13, 110-117.

[18] Engstler, M.; Ferrerogarcia, M.A.; Parodi, A.J.; Schauer, R.; Storzeckerlin, T.; Vasella, A.; Witzig, C.; Zhu, X.Y. (1994) Helv. Chim. Acta, 77, 1166-1174.

[19] White, C.L. ; Philippon, C.; Janakiraman, M.N.; Vasella, A.; Laver, W.G.; Air, G.M.; and Luo, M. (1995) J. Mol. Biol., 245, 623-634.

[20] Neres, J.; Buschiazzo, A.; Alzari, P.M.; Walsh, L. and Douglas, K.T. 2006) Anal. Biochem., 357, 302-304.

[21] Streicher, H. and Busse, H. (2006) Bioorg. Med. Chem. 14, 10471057; Streicher, H. (2004) Curr. Med. Chem. Anti-infective Agents, 3, 149-161.

[22] Ferrero-Garcia, M.A.; Sanchez, D.O.; Frasch, A.C.C. and Parodi, A. (1993) J. An. Asoc. Quim. Argent, 81, 127-132;

[23] Neres, J.; Buschiazzo, A.; Bonnet, P.; Edwards, P.N.; Alzari, P.M.; Bryce, R.A.; Kotian, P.L. and Douglas, K.T. (2007) Bioorg. Med. Chem., 15, 2106-2119.

[24] Watts, A.G.; Damager, I.; Amaya, M.L.; Frasch, A.C.; Buschiazzo, A.; Withers, S.G. and Alzari, P. (2003) J. Am. Chem. Soc., 125, 7532-7533.

[25] Buchini, S.; Buschiazzo, A. and Withers, S.G. (2008) Angew. Chem. Int., Ed., 47, 2700-2703.

[26] Berkowitz, D.B.; Karukurichi, K.R.; Salud-Bea, R.; Nelson, D.L. and McCune, C.D. (2008) J. Fluorine Chem., 129, 731-742.

[27] Schenkman, S.; Eichinger, D.; Pereira, M.E. and Nussenzweig, V. (1994) Апnи. Rev. Microbiol., 48, 499-523.

[28] Lantwin, C.B., Kabscli, W.; Pai, E.F. and Siegel, R.L.K. (1994) Proteins 18, 161-173.

[29] Siegel, R.L.K. and Comini, M.A. (2008) Biochimica Biophysica Acta, 1780, 1236- 1248.

[30] Heby, O.; Persson, L. and Rentala, M. (2007) Amino Acids, 33, 359-366.

[31] Chibale, K. (2002) ARKIVOC 9, 93-98;

[32] Maya, J.D.; Bollo, S.; Nunes-Vergara, L.J.; Squella, J.A.; Repetto, Y.; Morello, Y.; Morello, A.; Perie, J and Chauviere, G. (1995) Biochem. Pharmacol., 50, 1367-1371.

[33] Search recorded in five bibliographic databases: ISI Web of Science, Scifinder, Science Direct, ACS and Scopus, October, 2008.

[34] Bond, C.S.; Zhang, Y.H.; Berriman, M.; Cunningham, M.L.; Fairlamb, A.H. and Hunter, W.N. (1999) Structure, 7, 81-89.

[35] Hamilton, C.J.; Saravanamuthu, A.; Fairlamb, A.H.; Poupat, C. and Eggleston, I.M. (2005) Bioorg. Med. Chem., 14, 2266-2278.

[36] Garforth, J.; Yin, H.; McKie, J.H.; Douglas, K.T. and Fairlamb, A.H. (1997) J. Enzyme Inhib. Med. Chem., 12, 161-173.

[37] Chan, C.; Yin, H.; Garforth, J.; McKie, J.H.; Jaouhari, R.; Speers, P.; Douglas, K.T.; Rock, P.J.; Yardley, V.; Croft, S.L. and Fairlamb, A.H. (1998) J. Med. Chem., 41, 148-156.

[38] Benson, T.J.; McKie, J.H.; Garforth, J.; Borges, A.; Fairlamb, A.H. and Douglas, K.T. (1992) Biochem. J., 286, 9-11.

[39] Parveen, S.; Khan, M.O.F.; Austin, S.E.; Croft, S.L.; Yardley, V.; Rock, P. and Douglas, K.T. (2005) J. Med. Chem., 48, 8087-8097.

[40] Lima, L.M. and Barreiro, E.J. (2005) Curr. Med. Chem., 12, 23-59.

[41] Davioud-Charvet, E.; McLeish, M.J.; Veine, D.M.; Giegel, D.; Arscott, L.D.; Andricopulo, A.D.; Becker, K.; Muller, S.; Schirmer, R.H.; Williams, C.H. and Jr.; Kenyon, G.L. (2003) Biochemistry, 42, 13319-13330.

[42] Urig, S. and Becker, K. (2006) Semin. Cancer Biol., 16, 452-465.

[43] Lee, B.; Bauer, H.; Melchers, J.; Ruppert, T.; Rattray, L.; Yardley, V.; Davioud-Charvet, E. and Krauth-Siegel, R.L. (2005) J. Med. Chem., 48, 7400-7410.

[44] Hammond, D.J.; Cover, B. and Gutteridge, E.W.A (1984) Trans. $R$. Soc. Trop. Med. Hyg., 78, 91-95.

[45] Jacoby, E.M., Schlichting, I., Lantwin, C.B., Kabsch, W. and Krauth-Siegel, R.L. (1996) Proteins, 24, 73-80.

[46] Bonse, S., Santelli-Rouvier, C., Barbe, J., and Krauth-Siegel, R.L. (1999) J. Med. Chem., 42, 5448-5454.

[47] Saravanamuthu, A.; Vickers, T.J.; Bond, C.S.; Peterson, M.R.; Hunter, W.N. and Fairlamb, A.H. (2004) J. Biol. Chem., 279, 29493-29500.

[48] Chibale, K., Haupt, H., Saravanamuthu, A., Kendrick, H., Fairlamb, A.H., Yardley, V. and Croft, S.L. (2001) Bioorg. Med. Chem. Lett., 11, 2655-2657. 
[49] Duarte, C.D., Barreiro, E.J. and Fraga, C.A.M. (2007) Mini-Rev. Med. Chem., 7, 1108-1119.

[50] Fricker, S.P. (2007) Dalton Trans., 4907-4917.

[51] Allardyce, C.S.; Dorcier, A.; Scolaro, C. and Dyson, P.J. (2005) App. Organometal. Chem., 19, 1-10.

[52] Baird, I.R.; Mosi, R.; Olsen, M.; Cameron, B.; Fricker, S.P. and Skerli, R.T. (2006) Inorg. Chim. Acta, 359, 2736-2750.

[53] Mosi, R.; Baird, I.R.; Cox, J.; Anastassov, V.; Cameron, B.; Skerli, R.T. and Fricker, S.P. (2006) J. Med. Chem., 49, 5262-5277.

[54] Lowe, G.; Droz, A.S.; Vilaivan, T.; Weaver, G.W.; Tweedale, L.; Pratt, J.M.; Rock, P.; Yardley, V. and Croft, S.L. (1999) J. Med. Chem., 42, 999-1006.

[55] Sanchez-Delgado, R.A.; Navarro, M.; Lazardi, K.; Atencio, R.; Capparelli, M.; Vargas, F.; Urbina, J.A.; Bouillez, .A; Hubert, A.J. and Noels, A.F. (1998) Inorg. Chim. Acta., 528, 275-276.

[56] Navarro, M.; Lehmann, T.; Cisneros-Fajardo, E.J.; Fuentes, A.; Sanchez-Delgado, R.A.; Silva, P. and Urbina, J.A. (2000) Polyhedron, 19, 2319-2325.

[57] Navarro, M.; Cisneros-Fajardo, E.J.; Lehmann, T.; SanchezDelgado, R.A.; Atencio, R.; Silva, P.; Lira, R. and Urbina, J.A. Inorg. Chem., 40, 6879-6884.

[58] Aguirre, G.; Cerecetto, H.; Di Maio, R.; Gonzáles, M.; Montoya Alfano, M. E.; Jaso, A.; Zarranz, B.; Ortega, M.A.; Aldana, I. and Monge, A. (2004) Bioorg. Med. Chem., 14, 3835.

[59] Bastosa, A.M.B.; Silva, G.D.; Maia, P.I.D.; Deflon, V.M.; Batista, A.A.; Ferreira, A.V.M.; Botion, L.M.; Niquet, E. and Beraldo, H. (2008) Polyhedron, 27, 1787-1794.

[60] Urquila, C.; Vieites, M.; Aguirre, G.; Marin, A.; Solano, B.; Arrambide, G.; Nobia, P.; Lavaggi, M.M.; Torre, M.H.; Gonzáles, M.; Monge, A.; Gambino, D. and Cerecetto, H. (2006) Bioorg. Med. Chem., 14, 5503-5509.

[61] Gambino, D.; Otero, L.; Cerecetto, H.; Gonzalez, M. Uruguayan Patent No. 28563, 2004.

[62] Peres-Bebolledo, A.; Teixeira, L.R.; Batista, A.A.; Mangrich, A.S.; Aguirre, G.; Cerecetto, H.; Gonzalez, M.; Hernandez, P.; Ferreira, A.M.; Speziali, N.L. and Beraldo, H. (2008) Eur. J. Med. Chem., 43, 939-948.

[63] Otero, L.; Smircich, M.; Vieites, M.; Cingana, M.; Severino, P.C.; Terenzi, H.; Cerecetto, H.; Gambino, D. and Garat, B. (2007) J. Inorg. Biochem., 101, 74-79.

[64] Otero, L.; Vieites, M.; Boianí, L.; Denicola, A.; Rigol, C.; Opazo, L.; Olea-Azar, C.; Maya, J.D.; Morello, A.; Krauth-Siegel, R.L.; Piro, O.E.; Castelano, E.; Cerecetto, H.; Gambino, D.; Gonzalez, M. and Gambino, D. (2006) J. Med. Chem., 49, 3322-3331.

[65] Turrens, J.F.; Newton, C.L.; Zhong, L.; Hernandez, F.R.; Whitfield, J. and Docampo, R. (1999) FEMS Microbiol. Lett., 175, 217-221.

[66] Vieites, M.; Smircich, P.; Parajo-Costa, B.; Rodriguez, J.; Galaz, V.; Olea-Azar, C.; Otero, L.; Aguirre, G.; Cerecetto, H.; Gonzalez, M.; Barrio, A.G.; Garat, B. and Gambino, D. (2008) J. Biol. Inorg. Chem., 13, 733-735.

[67] Bocedi, A.; Gradoni, L.; Menegatti, E. and Ascenzi, P. (2004) Biochem. Biophys. Res. Commun., 315, 710-718.

[68] Silva, J.J.N.; Osakabe, A.L.; Pavanelli, W.R.; Silva, J.S. and Franco, D.W. (2007) Brit. J. Pharmacol., 152, 112-121.

[69] Mosi, R.; Baird, I.R.; Cox, J.; Anastassov, V.; Cameron, B.; Sherji, R.T. and Fricker, S.P. (2006) J. Med. Chem., 49, 5262-5272.
[70] Fricker, S.P.; Mosi, R.M.; Cameron, B.; Baird, I.; Zhu, Y.; Anastassov, V.; Cox, J.; Doyle, P.S.; Hansell, E.; Lau, G.; Langille, J.; Olsen, M.; Qin, L.; Sherji, R.; Wong, R.S.Y.; Santucci, Z. and Mckerrow, J.H. (2008) J. Inorg. Biochem., 102, 1839-1845.

[71] Cazullo, J.J. (2002) Curr. Top. Med. Chem., 2, 1257-1267.

[72] Scharfstein, J.; Schmitz, V.; Morandi, V.; Capella, M.M.; Lima, A.P.; Morrot, A.; Juliano, L. and Müller-Esterl, W. (2000) J. Exp. Med., 192, 1289-1300.

[73] Gelb, M.H.; Voorhis, W.C.V.; Buckner, F.S.; Yokoyama, K. Eastman, R.; E. P. Carpenter.; Panethymitaki, C.; Brown, K.A. and Smith, D.F. (2003) Mol. Biochem. Parasitol., 126, 155-163.

[74] Steverding, D.; Caffrey, C.R. and Sajid, M. (2006) Mini-Rev. Med. Chem., 6, 1025-1032.

[75] Roush, W.R.; Gonzfilez, F.V.; McKerrow, J.H. and Hansell, E. (1998) Bioorg. Med. Chem. Lett., 8, 2809-2812.

[76] Roush, R.W.; Cheng, J.; Reed, B.K.; Alvarez-Hernandez, A.; Hansell, E.; McKerrow, J.H. and Engel, C.J. (2001) Bioorg. Med. Chem. Lett., 11, 2759-2762.

[77] Jaishankar, P.; Doyle, P.S.; Hansell, E.; McKerrow, J.H.; Zhao, D.M. and Renslo, A.R. (2008) Bioorg. Med. Chem. Lett., 18, 624628.

[78] Porcal, W.; Cazzulo, J.J.; Hernandez, P.; Campillo, N.E.; Basombrı, M.A.; Boiani, M.; Paez, J.A.; Gonzalez, M.; Aguirre, G.; Castro, A.; Boiani, L.; Chidichimo, A.; Krauth-Siegel, R.S. and Cerecetto, H. (2007) J. Med. Chem., 50, 6004-6015.

[79] Doyle, P.S.; Zhou, Y.W.; Engel, J.C. and McKerrow, J.H. (2007) Antimicrob. Agents Chemother., 51, 3932-3939.

[80] Li, R.; Chen, X.; Gong, B.; Selzer, P.M.; Li, S.; Davidson, E.; Kurzban, G.; Miller, R.E.; Nuzum, E.; McKerrow, J.H.; Fletterick, R.J. (1996) Bioorg. Med. Chem., 4, 1421-1421.

[81] Ifa, D.R.; Rangel, C.R.; Alencastro, R.B.; Fraga, C.A.M. and Barreiro, E.J. (2000) J. Mol. Struc. THEOCHEM, 505, 11-17.

[82] Rodrigues, C.R.; Flaherty, T.F.; McKerrow, J.H.; Springer, C. and Cohen, F.E. (2002) Bioorg. Med. Chem. Lett., 12, 1537-1541.

[83] Du, X.; Hansell, Engel, J.C.; Caffrey, C.R.; Cohen, F.E. and Mckerrow, J.H. (2000) Chem. Biol., 7, 733-742.

[84] Du, C.X.; Guo, C.; Hansell, E.; Doyle, P.S.; Caffrey C.R., Holler T.P. McKerrow, J.H. and Cohen, F.E. (2002) J. Med. Chem., 45, 2695-2707.

[85] Greenbaum, D.C.; Mackey, Z.; Hansell, E.; Doyle, P.; Gut, J.; Caffrey, C.R.; Lehrman, J.; Rosenthal, P.J.; Mckerrow, J.H. and Chibale, K. (2004) J. Med. Chem., 47, 3212-3219.

[86] Fujii, N.; Mallari, J.P.; Hansell, E.J.; Mackey, Z.; Doyle, H.; Gut, Rosenthal, P. J. (2005) Bioorg. Med. Chem. Lett., 15, 121-123.

[87] Siles, R.; Chen, S.; Zhou, M.; Pinney, K.G. and Trawick, M.L. (2006) Bioorg. Med. Chem. Lett., 16, 4405-4409.

[88] Leite, A.C.L.; Lima, R.S.; Moreira, D.R.M.; Cardoso, M.V.O.; Brito, A.C.G.; Santos, L.M.F.; Hernandes, M.Z.; Kiperstok, A.C.; Lima, R.S. and Soares, M.B. P. (2006) Bioorg. Med. Chem., 14, 3749-3757.

[89] Leite, A.C.L.; Moreira, D.R.M.; Cardoso, M.V.O.; Hernandes, M.Z.; Pereira, V.R.A.; Silva, R.O.; Kiperstok, A.C.; Lima, M.S. and Soares, M.B.P. (2007) ChemMedChem,2, 1339-1345. 